\title{
STUDIES OF THE IONOSPHERE AND THEIR APPLICATION TO RADIO TRANSMISSION ${ }^{1}$
}

\author{
By S. S. Kirby, L. V. Berkner, and D. M. Stuart
}

\section{ABSTRACT}

Observations of the virtual height of the ionosphere and its variations carried out at the Bureau of Standards during the period of September 1930 to April 1933 are reported and discussed. The pulse method of Breit and Tuve was used with a visual recording technique developed by the Bureau of Standards.

In general, a number of layers were discernible, the major daytime layers being the lower or $E$ layer at about 100 to $120 \mathrm{~km}$ virtual height, an $F_{1}$ layer at about $180 \mathrm{~km}$ virtual height, and an $F_{2}$ layer at about $240 \mathrm{~km}$ virtual height. The relative electron densities of these layers were determined by measuring the critical penetration frequencies where possible. The $E$ and $F_{1}$ layer critical frequencies were highest at summer noon and fell off both diurnally and seasonally as the angle of the sun's rays with the vertical increased. Abnormally strong $E$ layer ionization occurred occasionally at irregular intervals. The $F_{1}$ layer showed magneto-ionic splitting during the day. There was some correlation between $F_{1}$ layer ionization and magnetic storms.

The $F_{2}$ critical frequency was greatest on a summer evening, and greater on a winter noon than on a summer noon. From this evidence it is believed that the $F_{2}$ critical frequency may be determined by some other factor than penetration, such as absorption.

Scattered reflections of long retardation were observed on frequencies considerably higher than the $F_{2}$ critical frequency.

\section{CONTENTS}

I. Historical summary

II. Experimental method.

III. Investigations of the $E$ layer

IV. Investigations of the $F_{1}$ layer

V. Investigations of the $F_{2}$ layer

VI. Scattered reflections

VII. Some correlations with results of radio transmission

\section{HISTORICAL SUMMARY}

Marconi's first successful trans-A tlantic radio transmission in 1901 aroused a great deal of discussion regarding the propagation of radio waves around the curvature of the earth's surface. Theoretical reasoning showed that the phenomena could not be due to diffraction alone. In $1902 \mathrm{~A}$. E. Kennelly ${ }^{2}$ published the first suggestion of an ionized upper region in the atmosphere in connection with radio wave propagation. He showed that this region, for the lower limit of which he calculated provisionally a height of $80 \mathrm{~km}$, would be conducting. It is interesting to note that Kennelly used the expression "electrically

1 Read at URSI meeting at Washington, Apr. 27, 1933, and at the Annual Convention of the I.R.E. at Chicago, June 26, 1933.

2 A. E. Kennelly, Electrical World \& Engineer, vol. 39, p. 473, Mar. 15, 1902.

23797-33-2 
conducting strata" indicating that he had in mind several layers. If we may quote one sentence from Kennelly's 1902 paper his ideas on this subject will be indicated clearly. He wrote: "It seems reasonable to infer that electromagnetic disturbances emitted from a wireless sending antenna spread horizontally outwards, and also upwards, until the conducting strata of the atmosphere are encountered, after which the waves will move horizontally outwards in a 50-mile layer between the electrically-reflecting surface of the ocean beneath, and an electrically-reflecting surface, or successive series of surfaces, in the rarified air above." A few months later Oliver Heaviside ${ }^{3}$ independently set forth the idea that a conducting layer in the upper atmosphere might guide radio waves.

The theory of propagation of light waves through a system of molecules was given by H. A. Lorentz ${ }^{4}$ in 1909 . This theory was applied to radio wave propagation in the ionosphere by Eccles ${ }^{5}$ and Larmor. ${ }^{6}$ Eccles assumed an upper layer so intensely ionized as to reflect the waves without penetration and an ionization of the middle atmosphere which bent the waves. He considered only the motions of the heavy ions. He showed that the action of free ions was to increase the phase velocity of the waves in the medium so that the index of refraction was decreased to a value less than unity. Thus the waves were bent by refraction rather than reflection. Larmor emphasized the importance of considering free electrons of such a long free path that absorption was negligible and sketched a theory of refraction based upon these ideas. Being lighter than the ions, comparatively few electrons were necessary to produce sufficient bending of the rays. The foundations for a theoretical discussion of the action of the ionosphere on radio wave propagation are to be found in these two papers.

In his 1912 paper and again in 1924, Eccles ${ }^{7}$ stated that two layers, one a high permanently ionized layer, and the other a lower layer ionized daily by sunlight, were required to explain the phenomena then observed.

Appleton and Barnett ${ }^{8}$ in 1925, reported direct evidence of the existence of a reflecting layer. They employed both the frequency change method and the angle of incidence method using a frequency of about $750 \mathrm{kc} / \mathrm{s}$. They estimated the virtual height to be about $80 \mathrm{~km}$. A few months later Breit and Tuve ${ }^{9}$ independently reported similar evidence using the pulse or group retardation method developed by them, and employing a frequency of about $4,200 \mathrm{kc} / \mathrm{s}$. At this time they reported virtual heights of $80 \mathrm{~km}$ and $160 \mathrm{~km}$. A comprehensive paper was published by each of these groups of workers a few months later. ${ }^{10}{ }^{11}$ In the latter paper Breit and Tuve reported virtual heights from about $90 \mathrm{~km}$ to $225 \mathrm{~km}$. In the light of later developments, it is evident that they were getting reflections from both $E$ and $F$ regions. Breit and Tuve at this time also used other frequencies such as $7,500 \mathrm{kc} / \mathrm{s}$, at which they sometimes received reflections but not always. They observed that reflections varied rapidly both in amplitude and position.

\footnotetext{
3 Oliver Heaviside, Encyclopedia Britannica, Tenth Edition, vol. 33, p. 215, Dec. 19, 1902.

4 Lorentz, Theory of electrons, Leipsig, 1909.

5 Eccles, Proc. Roy.Soc., 87 A, p. 79, 1912.

6 Larmor, Phil.Mag., vol. 48, p. 1025, 1924.

7 Eccles, Proc.Phys.Soc., vol. 37, pp. 3D and 48D, November 1924

8 Appleton \& Barnett, Nature, vol. 115, Mar. 7, 1925.

9 Breit and Tuve, Nature, vol. 116, p. 357, Sept. 5, 1925.

${ }_{10}$ Appleton and Barnett, Proc.Roy.Soc.A, vol. 109, p. 621, December 1925

11 Breit and Tuve, Phys.Rev., vol. 28, p. 554, September 1926.
} 
At about the same time, studies of the ionosphere were being made by Taylor and Hulburt ${ }^{12}$ using the skip distance method. They calculated daytime virtual heights of from 155 to $240 \mathrm{~km}$.

In 1927 Appleton ${ }^{13}$ working at $750 \mathrm{kc} / \mathrm{s}$ detected a sudden change in the virtual height of the layer during some early morning measurements, and concluded that there were 2 layers at night, one at a virtual height of about $100 \mathrm{~km}$ and the other at a virtual height of about $240 \mathrm{~km}$.

In 1928 Breit, Tuve, and Dahl ${ }^{14}$ reported daytime virtual heights from about $100 \mathrm{~km}$ to $225 \mathrm{~km}$ with multiples of the $225 \mathrm{~km}$ values.

In 1929 and 1930 Appleton and Green, ${ }^{15} 16$ working at about $3,000 \mathrm{kc} / \mathrm{s}$ reported evidence of sudden jumps of the virtual height of the layer in the daytime and concluded that the two layers, $E$ and $F$, existed both day and night. They also pointed out that this interpretation fitted in with the earlier results of Breit, Tuve, and Dahl.

In 1931 Schafer and Goodall, ${ }^{17}$ working at $1,604 \mathrm{kc} / \mathrm{s}$ and $3,088 \mathrm{kc} / \mathrm{s}$ simultaneously, found abrupt increases in virtual height during the late afternoon and corresponding decreases in the early morning. However, the afternoon increase in virtual height occurred about 2 hours earlier for $3,088 \mathrm{kc} / \mathrm{s}$ than for $1,604 \mathrm{kc} / \mathrm{s}$ and in the morning the virtual height for $1,604 \mathrm{kc} / \mathrm{s}$ decreased before that for $3,088 \mathrm{kc} / \mathrm{s}$. These results were interpreted as evidence of two layers.

In 1931 Gilliland, Kenrick, and Norton ${ }^{18}$ varied the frequency from 1,600 to $8,650 \mathrm{kc} / \mathrm{s}$ and found evidence that the 2 layers existed simultaneously during the day for frequencies between 3,000 and $5,000 \mathrm{kc} / \mathrm{s}$. They also discussed the effect of the $E$ layer on the retardation of pulses going to the $F$ layer and showed that for the criticalpenetration frequency long retardations should be expected.

Evidence that there are two or more layers has been found in practically all subsequent work of this type regardless of the method used. The frequency change method and the angle of incidence method were developed in England, and the pulse method by Breit and Tuve in the United States. The British school has used the frequency change method for normal incidence experiments almost exclusively until the last three years. Since then, it has taken up the pulse method of Breit and Tuve, probably because the complex phenomena observed at the higher frequencies could not be interpreted by the frequency change method. The American school has used the pulse method of Breit and Tuve exclusively for vertical incidence experiments from the beginning of this work in 1925 and has developed a technique for rapid and continuous measurements which facilitates detailed studies of layer changes. The German ${ }^{1920}$ school also has used the pulse method of Breit and Tuve.

Hafstad and Tuve ${ }^{21}$ extended the pulse method to measure the rate of change of the virtual height of a layer by the determination of the rate of change of radio-frequency phase of separate downcoming echoes.

12 Taylor and Hulburt, Phys.Rev., vol. 27, p. 189, February 1926.

13 Appleton, Nature, p. 330, Sept. 3, 1927.

14 Breit, Tuve, and Dahl, Proc.I.R.E., vol. 16, p. 1236, September 1928.

15 Appleton and Green, Nature, vol. 123, p. 445, Mar. 23, 1929.

16 Appleton and Green, Proc.Roy.Soc. A., vol. 128, p. 159, July 1930

17 Schafer and Goodall, Proc.I.R.E., vol. 19, p. 1434, 1931. 13 Gilliland, Kenrick and Norton, B.S. Jour. Research, vol. 7, p. 1083, 1931. Proc.I.R.E., vol. 20, p. 286,

${ }^{19}$ Goubau and Zenneck, Zeitschrift für hochfrequenztechnik, vol. 37, p. 207, 1931.

${ }^{20}$ Rukop and Wolf, Zeitschrift für technische physik, vol. 3, p. 132, 1932.

21 Hafstad and Tuve, Proc.I.R.E., vol. 17, p. 1786, 1929. 
T. L. Eckersley ${ }^{22}$ has developed and used a valuable method for long-distance studies of the ionosphere by means of facsimile transmissions.

In 1925 Appleton ${ }^{23}$ and Nichols and Schelleng, ${ }^{24}$ independently, pointed out that radio-wave refraction and absorption in the ionosphere should be considerably modified by the earth's magnetic field. Nichols and Schelleng showed that, in the simple cases in which a radio wave is propagated parallel or perpendicular to the earth's magnetic field, it would be split into 2 components by magnetic double refraction and, in general, one of these components would be more highly absorbed than the other. They also showed that there should be a critical absorption frequency at about $1,400 \mathrm{kc} / \mathrm{s}$.

In 1927 Breit ${ }^{25}$ showed quantitatively the effect of the earth's magnetic field on a ray propagated in any direction with respect to the terrestrial magnetic field. A few months later Appleton 262728 independently solved the same problem and gave an equation for the index of refraction which we shall use later on.

In 1928 Appleton and Ratcliffe ${ }^{29}$ found that downcoming waves of $750 \mathrm{kc} / \mathrm{s}$ in England were circularly polarized with a left-handed rotation due to the absorption of the other component and predicted that under similar circumstances in the southern hemisphere the waves would be circularly polarized with a right-handed rotation. In 1932 Green, ${ }^{30}$ working in Australia, reported experiments verifying this prediction.

In this brief historical review an attempt has been made to sketch the order of development of some of the principal phases of studies of the ionosphere. No attempt has been made to write a comprehensive review covering all the literature to date. Much of the more recent literature will be referred to during the discussion of our own work later on in this paper.

With regard to the nomenclature, the authors have adopted the general term "ionosphere" suggested by Dr. Watson Watt, to designate all the ionized region of the earth's atmosphere. We have previously called this region the Kennelly-Heaviside layer in honor of the men who contributed the original suggestions for this method of radio-wave propagation.

Although several layers are spoken of as if they existed separately with nonionized regions between them, it is not believed that such is the case, but rather that there exists one ionized region whose ionization varies with the height in such a manner that the retardations of radio waves fall into fairly definite groups. These retardations which determine the virtual height are due, first, to the actual height of the reflecting layer and, second, to the reduction in group velocity of the pulse caused by passing through lower ionized regions. The resultant virtual heights fall into fairly definite groups, but the real heights of the layers and the ionization between them is not known. The ionization between layers need not be less than that of the lower layer.

22 T. L. Eckersley, J.I.E.E., vol. 71, p. 405, 1932.

23 Appleton, Proc. Phys. Soc., vol. 37, p. 22 D, Feb. 15, 1925.

24 Nichols and Schelleng, Bell System Tech. Jour., vol. 4, p. 215, April 1925

${ }_{25}$ Breit, Proc.I.R.E., vol. 15, p. 709, August 1927.

${ }_{26}$ Appleton, Proc.U.R.S.I., p. 2, October 1927.

27 Appleton, J.I.E.E., vol. 71, p. 642, 1932.

28 Appleton and Naismith, Proc.Roy.Soc. A, vol. 137, 1932.

20 Appleton and Rateliffe, Proc. Roy.Soc. A, vol. 117, p. 576, 1928.

30 Green, Radio Research Board Report no. 2, Melbourne. 


\section{EXPERIMENTAL METHOD}

The observations reported in this paper were carried out during the period of September 1930 to April 1933, as one part of a program to obtain more complete information than has been heretofore available about the ionosphere and its variations, and their relation to radio transmission.

The method used was the "pulse" or group retardation method of Breit and Tuve. ${ }^{31}$ This consists of the transmission of a short pulse of about $2 \times 10^{-4}$ seconds' duration. Part of this pulse travels along the ground to the receiving set and is called the "ground" or reference pulse. Part of the pulse also travels from the ground to any reflecting or refracting medium and back to the ground one or more times. From the measurable difference in time between the arrival of the ground wave and the reflected waves, a virtual height can be computed for the source of each reflection. The virtual height in kilometers as determined by these time differences is indicated directly by means of suitable apparatus at the receiving station.

It has been shown that the existence of free ions in space causes a reduction in the refractive index ${ }^{32} 3334$ which, when sufficient, results in the complete bending of an electromagnetic wave back to the earth. When the angle of incidence is nearly normal, and the frequency is known, the refractive index can be computed, and the ion content at the virtual height indicated can be estimated. In this discussion this reduction in refractive index is stated in all cases in terms of an equivalent electron density. The effect of a heavy ion will be proportional to the square of its charge and inversely proportional to its mass. A plane wave solution of Maxwell's equations shows that, for a wave propagated in a medium of dielectric constant $\epsilon$ and conductivity $\sigma$, the index of refraction is given by

$$
n=\sqrt{\frac{\epsilon}{2}+\sqrt{\frac{\epsilon^{2}}{4}+\left(\frac{2 \pi c^{2} \sigma}{\omega}\right)^{2}}}
$$

where $c=$ velocity of light

$$
\omega=2 \pi \text { times the frequency. }
$$

It is shown by Epstein ${ }^{35}$ that unless the conductivity $\sigma$ is negligible, total refraction cannot occur. When $\sigma$ is neglected, the refractive index becomes

$$
n=\sqrt{\epsilon}=\sqrt{1-\Delta \epsilon}
$$

where $\Delta \epsilon=$ reduction in dielectric constant due to free electrons. From Snell's law $n \sin \phi_{r}=\sin \phi$ where $\phi_{r}=$ angle of refraction and $\phi=$ angle of incidence. Then at the apex of the ray path $\sin \phi_{r}=1$ and $n=\sin \phi=\sqrt{1-\Delta \epsilon}$

From the work of Lorentz it has been shown that the index of refraction of a frictionless electron gas is given by

$$
n^{2}=1-\frac{4 \pi N e^{2}}{\omega^{2} m+a\left(4 \pi N e^{2}\right)}
$$

\footnotetext{
31 See footnotes 8 and 10, p. 16. Also Breit and Tuve, Terr. Magnetism, vol. 30, p. 15, March 1925.

${ }_{33}^{32}$ See footnotes 3,4 , and 5, p. -

33 Baker and Rice, Jour. A.I.E.E., vol. 45, p. 535, 1926.

34 Pedersen, Propagation of radio waves, Ch. 6, Copenhagen, 1927.

35 P. S. Epstein, Proc. National Academy of Science, 1930, pp. 37 and 627.
} 
where

$N=$ number of electrons per $\mathrm{cm}^{3}$

$\omega=$ angular frequency

$e=$ electronic charge in esu.

The value of the constant " $a$ " has been the subject of considerable discussion in recent literature. Lorentz put and stated that

$$
a=\frac{1}{3}+S
$$

the value of the constant $S$ would in general be difficult to determine. He has, however, shown that $S=0$ for a medium, the scattering elements of which have a regular cubical arrangement.

The earlier writers ${ }^{36}$ on the theory of the Kennelly-Heaviside layer put $a=0$ in their equations. This resulted in a value of

$$
\Delta \epsilon=\frac{4 \pi N e^{2}}{\omega^{2} m}
$$

More recently, however, Appleton ${ }^{37}$ has called attention to the fact that " $a$ " probably has a value different from zero. Hartree ${ }^{38}$ has advanced reasons for believing that, in a medium such as the ionosphere, the value of " $a$ " is very nearly equal to $1 / 3$.

Because of the uncertainty concerning the value of " $a$ ", we have used both the value of 0 and $1 / 3$ for numerical calculations.

From equation (3)

$$
n=\sin \phi=\sqrt{1-\frac{4 \pi N e^{2}}{\omega^{2} m+a\left(4 \pi N e^{2}\right)}}
$$

When $\phi$ is made small by locating the transmitter and receiver near together, $\sin ^{2} \phi=0$ very nearly, and selecting $f_{c}$ as the lowest frequency at which the wave passes through the layer (the critical frequency) we have

$$
\begin{aligned}
& \text { putting } a=\frac{1}{3} \text { in (3) } \quad N=1.86 \times 10^{-8} f_{c}^{2} \\
& \text { or, putting } a=0 \text { in (3) } \quad N=1.24 \times 10^{-8} f_{c}^{2}
\end{aligned}
$$

The value of $N$ is taken as a measure of the maximum ionization of the layer.

It has been shown ${ }^{39}$ that the refractive index is modified by the earth's magnetic field. In general, two refractive indices are possible depending upon the direction of the wave normal with respect to that of the magnetic field.

Following Appleton, ${ }^{40}$ if we assume that friction is small, the index of refraction is given as a function of the frequency by

$$
n^{2}=1+\frac{2}{2 \alpha-\frac{\gamma_{T}^{2}}{1+\alpha} \pm \sqrt{\frac{\gamma_{T}^{4}}{(1+\alpha)^{2}}}+4 \gamma_{L}^{2}}
$$

${ }^{36}$ See footnotes 4, 5, 6, p. 16; 32, and 33, p. 19.

37 See footnote 26, p. 18.

38 Hartree, Proc. Cambridge Phil. Soc., vol. 27, p. 143.

${ }^{39}$ See footnotes $22,23,24$, and 11, pp. 18 and 16.

40 See footnotes 25,26 , and 27, p. 18 . 
where

$$
\begin{aligned}
\alpha & =-\frac{m \omega^{2}}{4 \pi N e^{2}}-a \\
\gamma_{L} & =\frac{m \omega\left(\frac{H_{L^{e}}}{m c}\right)}{4 \pi N e^{2}} \\
\gamma_{T} & =\frac{m \omega\left(\frac{H_{T^{e}}}{m c}\right)}{4 \pi N e^{2}}
\end{aligned}
$$

$H_{L}$ and $H_{T}$ are respectively the components of the earth's magnetic field along and at right angles to the wave normal for any direction of propagation with respect to the terrestrial magnetic field.

From this it is deduced that $n=0$ when

$$
\begin{aligned}
& 1+\alpha=0 \\
& 1+\alpha= \pm \sqrt{\gamma_{L}^{2}+\gamma_{T}^{2}}= \pm \gamma
\end{aligned}
$$

From the equation $1+\alpha=0$ we have

$$
f_{c}^{\prime \prime}=\sqrt{\frac{N_{\max }}{\pi} \frac{e^{2}}{m}} \text { putting } a \text { of eq. (3) }=0
$$

or

$$
f_{c}^{\prime \prime}=\sqrt{\frac{2}{3} \frac{N_{\max }}{\pi} \frac{e^{2}}{m}} \quad \text { putting } a \text { of eq. (3) }=\frac{1}{3}
$$

when this ray just penetrates the layer. This is seen to be the critical frequency of the ordinary ray denoted by $f_{c}^{\prime \prime}$. Estimates of electron density on the basis of this critical frequency are seen to be independent of the earth's magnetic field.

From the roots involving $\gamma$ we have for $a=1 / 3$

$$
\begin{gathered}
f_{1}^{\prime}=\frac{-\frac{H e}{2 \pi m c}+\sqrt{\left(\frac{H e}{2 \pi m c}\right)^{2}+4 \cdot \frac{2 N e^{2}}{3 \pi m}}}{2} \\
f_{2}^{\prime}=\frac{\frac{H e}{2 \pi m c}+\sqrt{\left(\frac{H e}{2 \pi m c}\right)^{2}+4 \cdot \frac{2 N e^{2}}{3 \pi m}}}{2}
\end{gathered}
$$

or $f_{2}{ }^{\prime}-f_{1}^{\prime}=\frac{H e}{2 \pi m c}=1,455 \mathrm{kc} / \mathrm{s}$, assuming a value of $H$, the total terrestrial magnetic field, of 0.52 gauss for $180 \mathrm{~km}$ height at Washington.

It appears that there are two possible critical frequencies for the extraordinary ray. It will be seen, however, that the ray will ordinarily travel only until $N$ is sufficiently large to return it, and it cannot therefore reach such an electron density as to cause $f_{1}^{\prime}$ to exist.

Then

$$
f_{2}^{\prime}=+\frac{\frac{H e}{2 \pi m c}+\sqrt{\left(\frac{H e}{2 \pi m c}\right)^{2}+4 f_{c}^{2}}}{2}
$$


Values of $f_{2}^{\prime}$ are plotted with respect to $f_{e}^{\prime \prime}$ for the $F_{1}$ layer in figure 1 and show the two frequencies, one which is called by Appleton the ordinary and the other the extraordinary ray which penetrate to the same electron densities. It can be seen that the critical frequencies for the two rays will also have this relation. The difference between values of $f_{c}^{\prime \prime}$ and $f_{2}^{\prime}$ is seen to approach a constant value of

$$
1 / 2\left(\frac{H e}{2 \pi m c}\right)=728 \mathrm{kc} / \mathrm{s}
$$

at very high frequencies. It has also been shown that the two rays have different polarizations and are attenuated differently. ${ }^{41}$

From the foregoing, two methods of study of the ionosphere are suggested: (1) To observe the variations in virtual height and am-

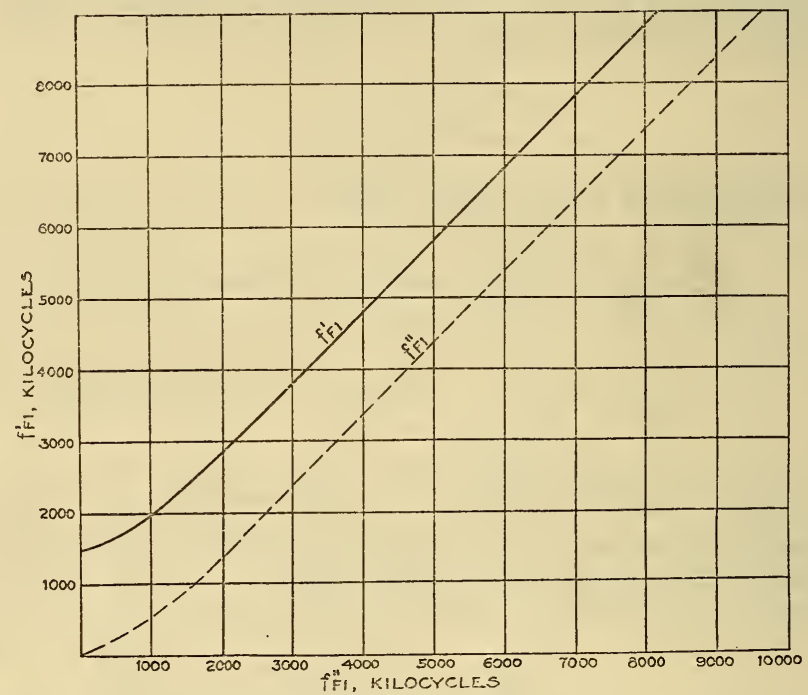

FIGURE 1.-Graphs showing the frequency separation of the critical frequencies of the ordinary and extraordinary rays due to magnetic double refraction at $180 \mathrm{~km}$ height at Washington, D.C. $f_{F}{ }^{\prime \prime}{ }_{1}$ denotes ordinary ray critical frequency for $F_{1}$ layer. $f_{F 1}^{\prime}$ denotes extraordinary ray critical frequency for $F_{1}$ layer.

plitude at constant frequency as ionization or recombination occurs with changing time, and (2) to observe the variations in virtual height and amplitude as the frequency is changed so rapidly that variations with time can be neglected. This paper relates chiefly to results obtained by the second method.

For the successful application of this method, a large number of observations at various frequencies throughout the range in which reflections are returned must be made during a period so short that changes due to ionization or recombination are not very appreciable. Each transmission must be so selected, and be made so short that the probability of creating interference is negligible. It is possible to make sufficiently rapid measurements except during periods when violent changes are taking place in the layers.

In practice, the transmissions were limited to a minute or less, and the run through the portion of the spectrum in which reflections were

${ }^{41}$ Appleton and Builder, Proc. Phys. Soc., vol. 45, part 2, no. 247. 
returned required from 30 to 60 minutes. In order to avoid missing any of the critical ranges, frequency changes must be made in steps of not more than $200 \mathrm{kc} / \mathrm{s}$. Generally, the changes were made in steps of $100 \mathrm{kc} / \mathrm{s}$ or even less.

Because of the narrow frequency bands within which the critical frequencies occur, the transmitter used had a low-power oscillator of good frequency stability followed by a multi-stage amplifier which was keyed. Sufficient power is necessary to show small reflections occurring at critical frequencies through high atmospheric noise. The power was increased from time to time during the study until, at the last, somewhat more than $1 \mathrm{kw}$ was in use. Single-wire horizontal high-angle radiators were employed.

A double-detection receiver having linear detector characteristics and operating a d-c amplifier of the bridge type was used to furnish the energy to an oscillograph galvanometer. The galvanometer was placed at the center of the bridge and had an electrical bias at all times, so that high resolution was possible. A light beam, reflected from the galvanometer, was projected from a three-sided rotating mirror and thence to a translucent celluloid screen. The triplecontact chopper at the transmitter and the rotating mirror at the receiver were rotated by means of synchronous motors operating from the same power supply. As the pulsing frequency was $3 / 2$ times the line frequency, spurious noises, synchronous with line frequency, did not break the base line established by the galvanometer, and could be separated from pulses originating at the transmitter which do break this base line. Measurements of virtual height were made by bringing the beginning of each reflected pulse to a reference line. This was accomplished by rotating the motor frame through a known angle with a micrometer screw calibrated directly in kilometers. The ground, or reference pulse, was brought to a second reference line located ahead of the first to correct for the time of travel of the ground pulse.

Large variations in the amplitude of various reflections (frequently in the order of $1000: 1$ in field intensity) were found. No attempt was made to observe the relative amplitudes directly on the oscillograph screen. Instead a calibrated attenuator in the intermediatefrequency amplifier was used to reduce the amplitude of the pulse to a standard value for measurement, and the actual amplitude was determined from the attenuator setting. This method served several purposes: (1) It eliminated the effect of the second detector characteristic on comparisons of amplitude; (2) it corrected for the error due to the appreciable (though very small) time required for the transmitted pulse to rise from zero to full amplitude; and (3) it made possible the measurement of very small reflections.

As it was necessary to move the equipment during the period of these experiments, the transmissions were made over three different paths. The transmitting station was finally located at Beltsville, Md., with the receiving station directly south at Meadows, Md., $25 \mathrm{~km}$ distant. The ground path of the earlier transmissions was $20 \mathrm{~km}$.

\section{INVESTIGATIONS OF THE E LAYER}

At the lower frequencies, reflections are returned from the $E$ layer. The virtual height ranges consistently from about $100 \mathrm{~km}$ at frequencies in the broadcast band (550 to $1,500 \mathrm{kc} / \mathrm{s}$ ) to about $120 \mathrm{~km}$ 
at frequencies near the critical frequency. These heights do not vary much between day and night conditions. In the daytime the reflections at upper broadcast frequencies are very small or entirely missing, and are larger in winter than in summer. As the frequency is increased these reflections become very large in amplitude. In the neighborhood of the critical frequency, a number of phenomena usually are observed in the following order as the frequency is increased: (1) The virtual height increases rapidly to large values, (2) the amplitudes decrease rapidly, all reflections frequently disappearing entirely; (3) further increases in frequency cause a decrease in virtual height to $F$-layer values. Some variations of the character of these phenomena are observed from time to time, especially during periods when the absorption increases sufficiently to cause reflections to disappear.

This critical frequency is the lowest frequency which can pass through the $E$ layer and is taken as a measure of the maximum

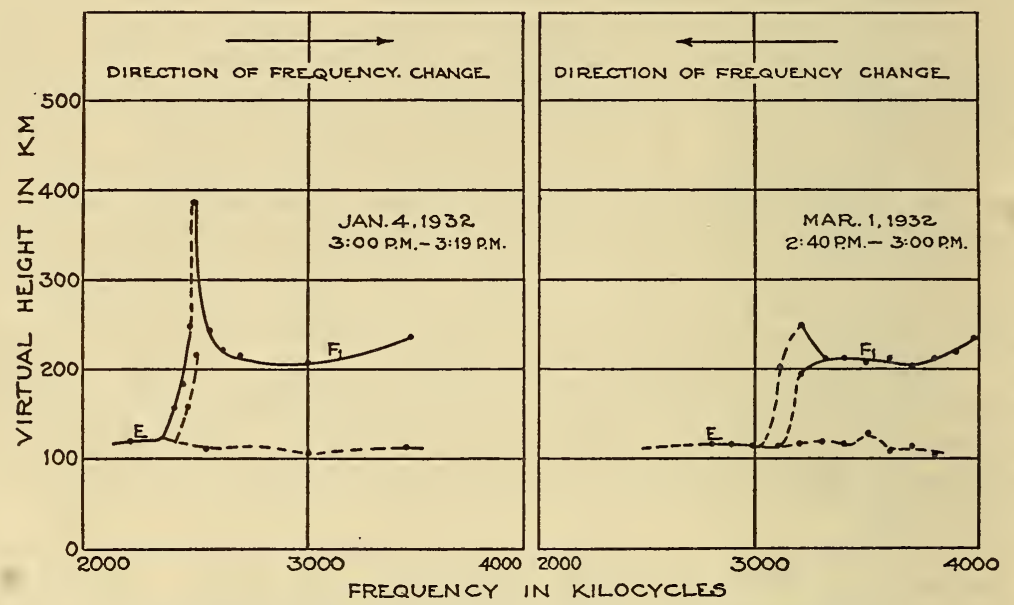

FigURe 2.-Typical cases of $E$ layer critical frequency.

ionization of the layer. It is termed the $E$ critical frequency and here represented by the symbol $f_{E}$.

Typical cases of $E$-layer critical frequency are shown in figure 2. This phenomenon appears to be identical with that observed by Schafer and Goodall ${ }^{42}$ and others, who held the frequency constant during a decrease in critical frequency due to recombination. The long retardation at critical frequency has been discussed by a number of writers, ${ }^{43} 444^{45}$ and occurs when the frequency is just high enough to permit the pulse to pass through the layer.

Determinations of critical frequency are made by varying the frequency through the range in which these phenomena are observed. The results of a large number of determinations throughout the $2 \frac{1}{2}$-year period show that (with certain exceptions discussed later) the variation of $f_{E}$ has certain quite regular characteristics during the daytime: (1) There is a regular diurnal variation, quite smooth,

42 See footnote 16, p. 17.

43 Appleton, Proc.Phys.Soc., vol. 42, p. 321, 1930.

44 See footnote 17, p. 17.

45 See footnote 27, p. 18. 
$f_{E}$ rising in the morning and ffalling in the afternoon; (2) the maximum occurs near local apparent noon, and the characteristic

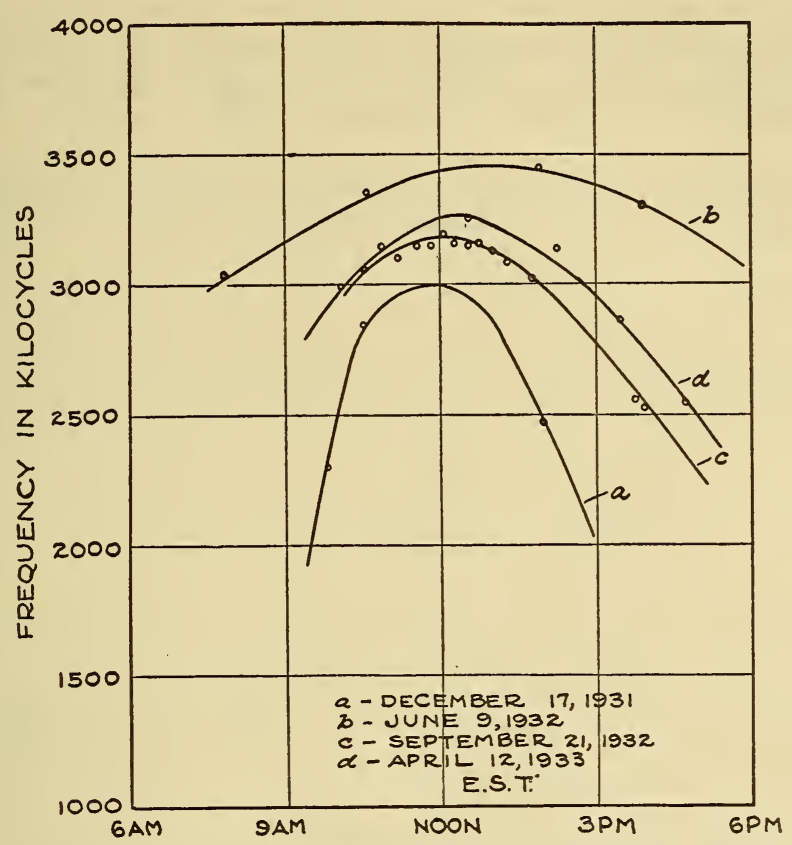

FIGURE 3.-Typical diurnal variations of $f_{E}$ selected for days during the various seasons.

is quite flat during this period; (3) these noon-maximum-values have a seasonal variation, but very little day-to-day variation.

Figure 3 shows typical diurnal variations of $f_{E}$ during selected days in each of the four seasons. Figure 4 shows a plot of a large number of values of $f_{E}$ taken in the early afternoon, grouped around the dates indicated. These figures show the seasonal change in diurnal variation of $f_{E}$. Figure 5 shows the annual variation of the maximum values of $f_{E}$ over an extended period. A few observations taken shortly after noon but corrected to noon by extrapolation from figure 4 , are included.

From the regularity of the daytime diurnal and seasonal characteristics, it appears that the sun is the chief ionizing agency during the day. From these figures it can be estimated that the annual varia-

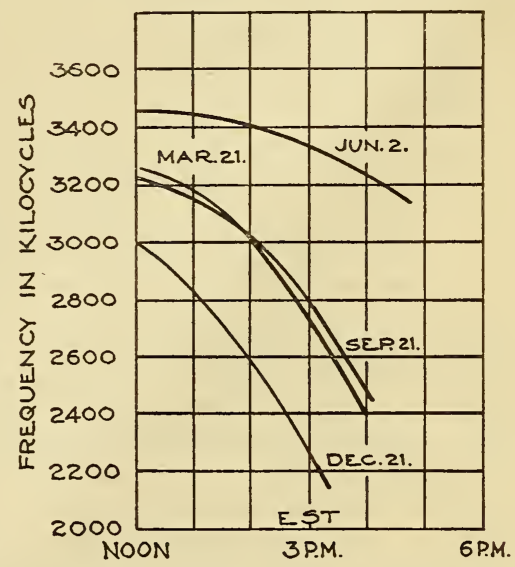

FIGURE 4.-This figure shows graphs of a large number of $E$ critical frequencies taken in the early afternoon and grouped around the dates indicated. tion in noon maximum of $f_{E}$ during this period was from about 3,000 $\mathrm{kc} / \mathrm{s}$ in December to $3,400 \mathrm{kc} / \mathrm{s}$ in June. This estimate is subject to 
certain limitations, in that daily observations were not made. There may also be slight differences in the opinions of various observers in the assignment of an exact frequency to be called "critical" for a phenomenon actually occurring through a narrow band of frequencies.

Taking the ionization as proportional to $\left(f_{E}\right)^{2}$, the ratio of maximum ionization from summer to winter values is seen to be about 1.3 to 1 .

As the frequency is increased above $f_{E}$, and large reflections are returned from the $F$ layer, $E$-layer reflections continue to appear but

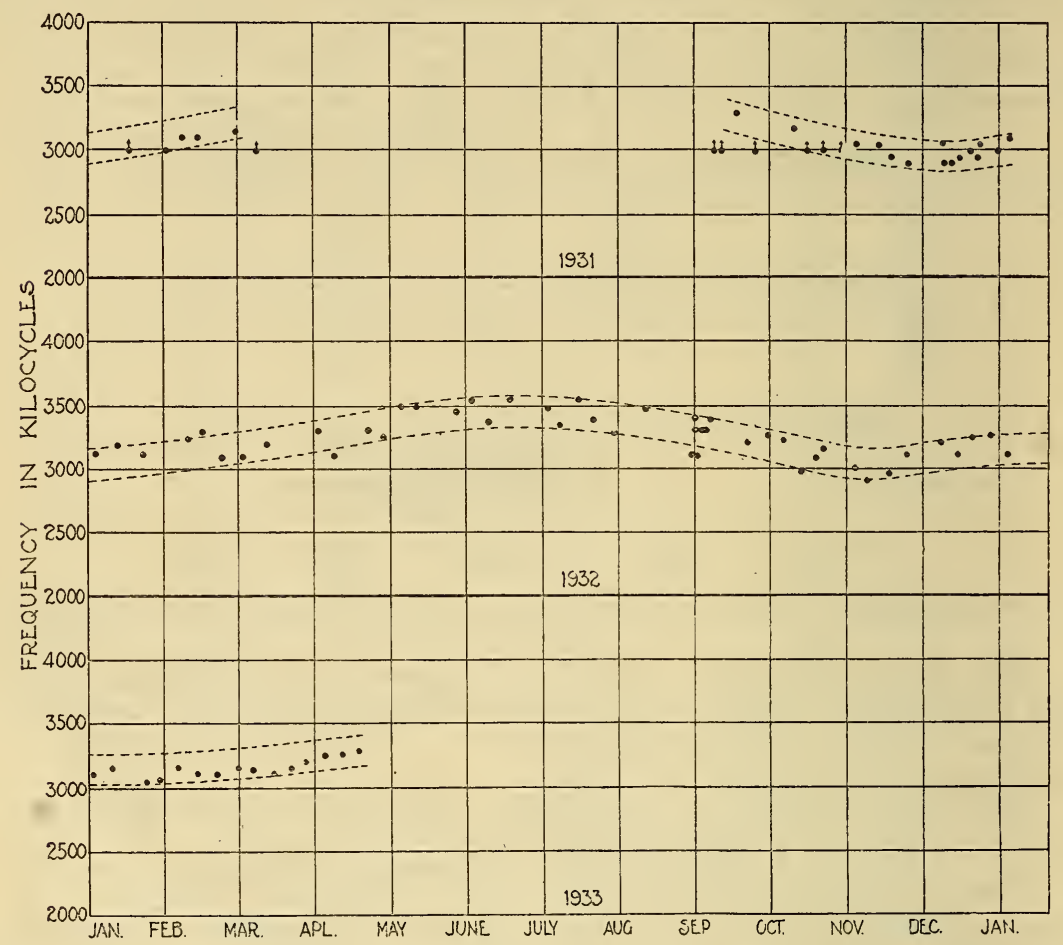

Figure 5.-Noon maximum values of $f_{E}$ for 1931, 1932, and 1933.

These values do not include occasional random high values of ionization discussed in text.

with very diminished amplitudes. (See fig. 2.) It has been suggested by some writers that this is due to a small amount of energy reflected from the comparatively sharp boundary of the lower region. Gilliland, Kenrick, and Norton ${ }^{46}$ show that the reflection coefficients are of approximately the correct magnitude. Magneto-ionic effects might also account for such reflections within certain frequency ranges. By a further study of these reflections it may be possible to obtain a more perfect understanding than now exists of the structure of this layer.

Occasionally reflections of great magnitude, sufficient to return a number of multiples, are returned from the $E$ layer at frequencies

46 See footnote 17, p. 17. 

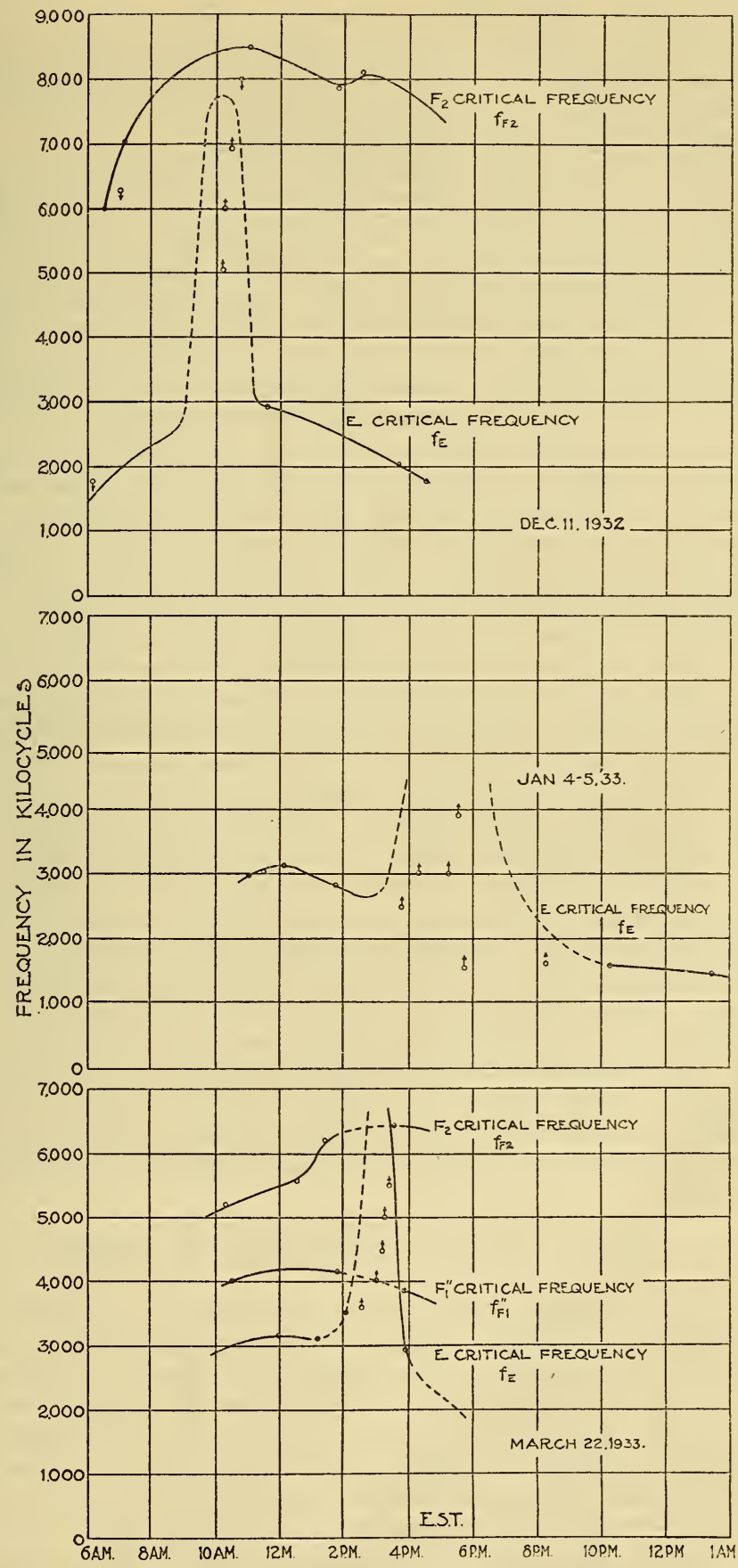

FIgURE 6.-Examples of occasional random high values of $f_{E}$.

0 indicates observations. $\delta$ indicates critical frequency is greater than observed frequency. $q$ indicates critical frequency is less than observed frequency. 
considerably higher than the usual values. Such phenomena have been observed when regular $f_{E}$ determinations were being made and are illustrated in figure 6 . It has been suggested ${ }^{47}$ that this phenomenon may be due either to a focussing effect from the $E$ layer, or to a sudden abnormal increase in E-layer ionization.

Because of the unexpected appearance of this phenomenon and the rapidity with which it takes place, it has been impossible up to the present time to make determinations of $f_{E}$ during its appearance. It has not been possible, therefore, to determine the manner in which $f_{E}$ varies. In view of the fact that the upper layers are frequently completely blanketed out for all frequencies, it appears that an increase in ionization may be the cause, and it is believed that $f_{E}$ is increased to abnormally high values. Determinations of critical frequencies for the upper layers during this phenomenon have indicated that these layers were not affected. (See fig. 6.) An examination of the magnetic character of days on which such phenomena are observed shows that they occur on both magnetically quiet and disturbed days. ${ }^{48}$ The phenomena have been observed most frequently in the evening or at night. It has been suggested ${ }^{49}$ that the high charges in a thunderstorm might account for abnormal E-layer ionization, but such occurrences have been observed during perfectly clear as well as overcast weather. Ranzi ${ }^{50}$ finds that some connection may exist between these high ionizations of the E-layer and low barometric pressures. As yet no comparison has been made with such meteorological data.

The variations of $f_{E}$ are found to be much less regular at night than during the daytime. The critical frequencies range from the lower part of the broadcast band ( 550 to $1,500 \mathrm{kc} / \mathrm{s}$ ) to values somewhat above the broadcast band at about 2 a.m. from night to night. The frequent appearance during the late afternoon and evening of the phenomenon of abnormally large $E$-layer reflections, which blanket out the upper layers on frequencies higher than normal, is usually followed by night values of $f_{E}$ which are higher than those found on other nights. This fact supports the view that the occasional strong $E$-layer reflections occurring at the higher frequencies are due to high ionization. It is possible that the normal process of recombination may be delayed under these circumstances, thus causing a considerable variability in ion content of the $E$ layer from night to night. It appears that this ionizing force acts independently of the direct radiation of the sun.

\section{INVESTIGATIONS OF THE $F_{1}$ LAYER}

As the frequency is increased above $f_{E}$ during the daytime in summer, the virtual heights fall to values between 185 and $250 \mathrm{~km}$, and then again increase and indicate a second critical frequency with phenomena somewhat similar to those observed for the $E$ critical frequency. Figures 7, 8, and 9 illustrate typically this phenomenon for the various times of the day during the spring and summer seasons. During the early morning and the late afternoon the phenomenon is much less distinct, and seems to disappear entirely during the night. Likewise, during the winter season it becomes less distinct than during the

47 Schafer and Goodall, Proc.I.R.E., vol. 20, p. 1131, 1932

18 See footnote 27, p. 18 .

49 C. T. R. Wilson, Proc.Phys.Soc., vol. 37, p. 32D, 1924.

50 Ranzi, Nature, vol. 130, p. 369, Sept. 3, 1932. 


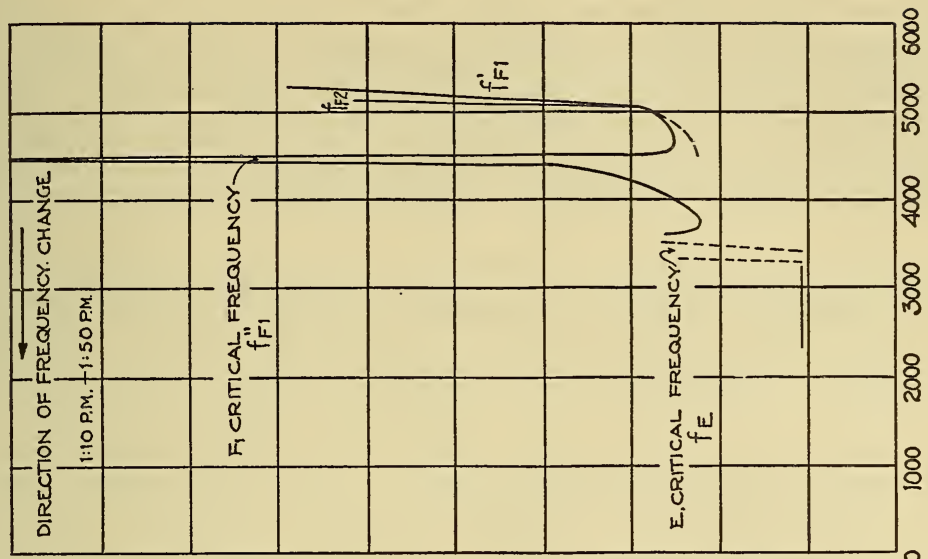

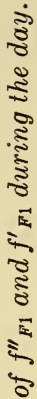

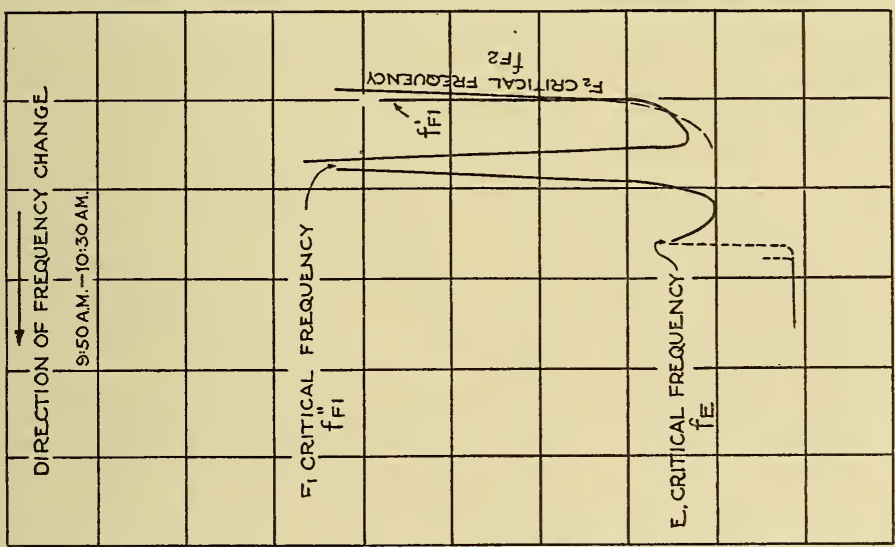

8.8 .

$8 \frac{1}{5}$

กิㄴ

U

81.

文

82 क

m-

$8 \mathrm{u}$

弪 :

$8)_{0}^{\circ}$

ㄴ.

崩 14.

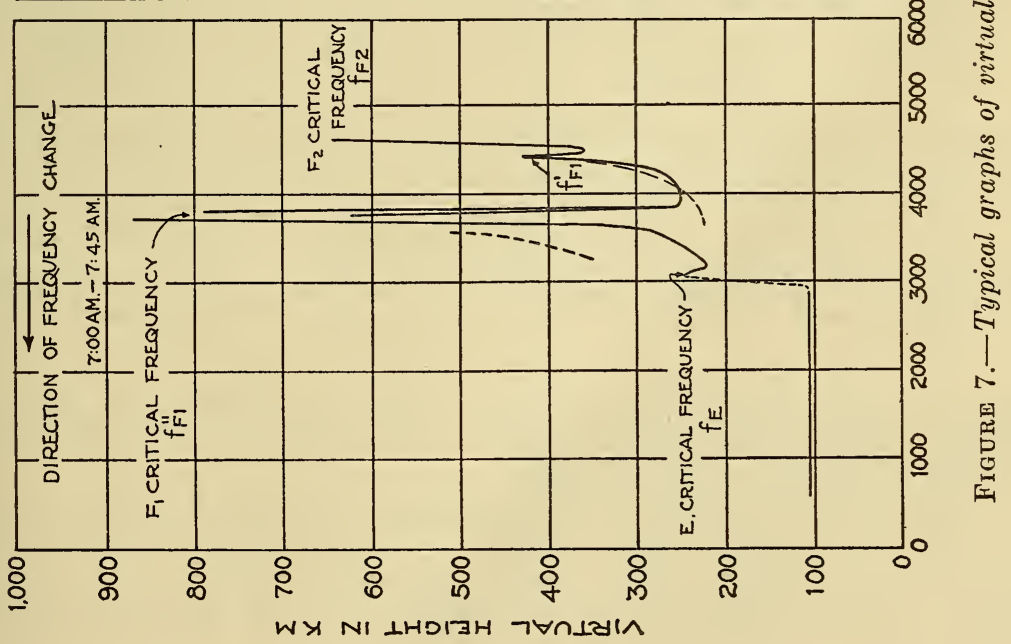


summer. Figure 10 illustrates this seasonal change during the afternoon.

Because of the regular occurrence of this effect and its similarity to that occurring at the maximum ionization of the $E$ layer, it is believed that it indicates a critical frequency representing a maximum ionization of a quite distinct layer ${ }^{51}$ in the $F$ region during the daytime. We therefore refer to this layer as the $F_{1}$ layer because of its apparent merging into a general $F$. layer under the conditions out-
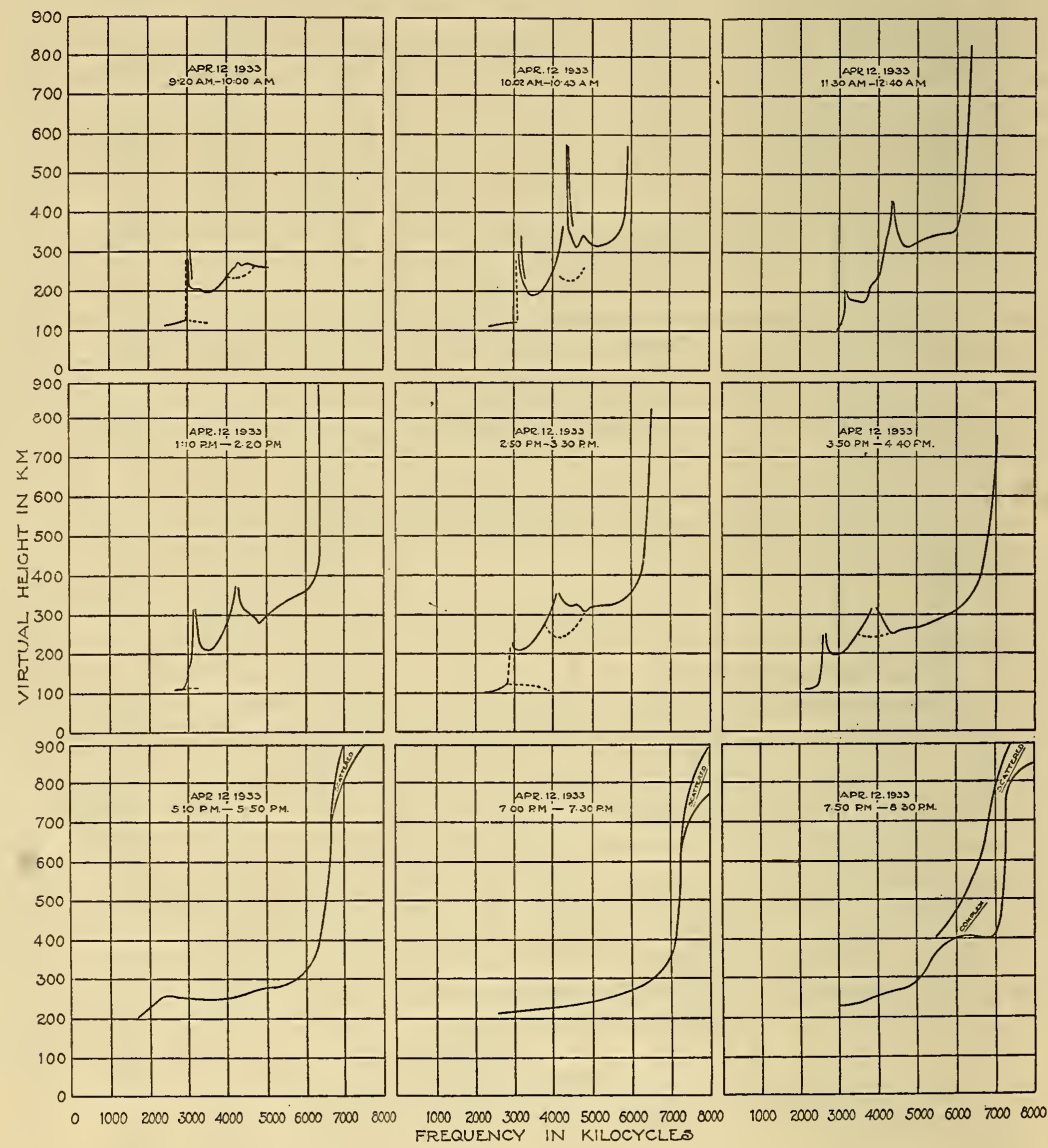

FIGURE 8.-Typical graphs of virtual height vs. frequency showing diurnal changes of retardations at $f^{\prime \prime}$. Doited curves indicate small reflections from $F_{1}^{\prime}$ ( $A$ pr. 12, 1933).

lined. This layer has a maximum ionization indicated by the $F_{1}^{\prime \prime}$ critical frequency denoted here as $f^{\prime \prime}{ }_{F 1}$. We refer to the layer found above the $F_{1}$ layer as the $F_{2}$ layer.

In support of the view of the stratification of the $F$ region during the daytime is the fact that while the virtual heights for frequencies less than $f^{\prime \prime}{ }_{F 1}$ show no direct relation to the variation of the virtual heights of the $F_{2}$ layer, the virtual heights for these same frequencies take on a direct relation to $F_{2}$ layer heights when $f^{\prime \prime}{ }_{F_{1} 1}$ has fallen beiow

51 Eckersley, J.I.E.E., vol. 71, p. 405, 1932. 
them. This indicates a separate $F_{1}$ layer whose ionization screens waves of frequencies below its critical value from the $F_{2}$ layer.

A typical graph showing the diurnal variation of $f^{\prime \prime} F_{1}$ and its relation to the other critical frequencies is shown in figure 11. From the nature of these variations, it can be concluded that, like the ordinary ionization of the $E$ layer, the ionization of the $F_{1}$ layer is apparently caused by radiation from the sun, and largely follows the diurnal and annual phases of the sun in the same manner as the ordinary variations of the $E$ layer.

The difference between $f_{E}$ and $f^{\prime \prime}{ }_{F 1}$ is such that the retardation effects found near the critical frequencies ordinarily appear to overlap. (See figs. 7 and 8.) Under these conditions, the virtual heights would always be very much in excess of the real height. At some times, virtual heights of the $F_{1}$ layer as low as 185 $\mathrm{km}$ are observed. If the virtual height of the $F_{1}$ layer is at all stable, this may be the nearest approach to the real height obtained.

The virtual heights of the long retarded reflections at $f^{\prime \prime}{ }_{F 1}$ vary rapidly through small frequency ranges, but may remain for a considerable period at great values, often in excess of 1,200 to $1,500 \mathrm{~km}$.

As the frequency is increased through $f_{F 1}^{\prime \prime}$, in addition to the main reflections

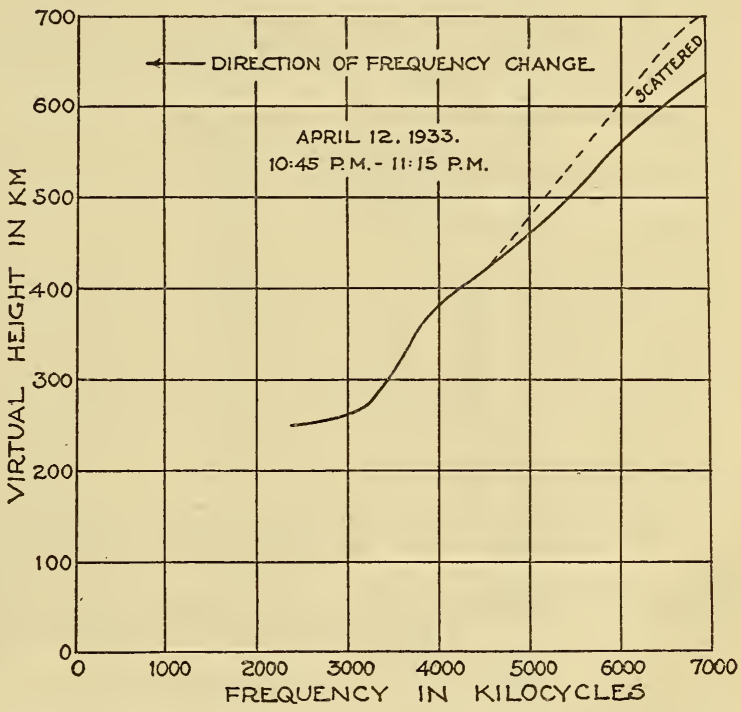

FIgURE 9.-Evening values of virtual height for Apr. 12, 1933. of large amplitude and increasing retardation, small reflections sometimes in the order of $1 / 1,000$ of the amplitude of the main reflections are returned from virtual heights corresponding to $F_{1}$ or $F_{2}$ layers. These are shown as the dotted curves in figures 7 and 8 . Such reflections might be attributed either to magneto-ionic double refraction in which this reflection represents the extraordinary ray, or to the effect of a comparatively sharp boundary.

It is seen from figures 12 and 13 that this small reflection increases in amplitude as the frequency is increased, and appears to go through a second critical frequency about $800 \mathrm{kc} / \mathrm{s}$ above $f^{\prime \prime}{ }_{11}$. From figure 1 it is seen that this separation is about that to be expected for the two critical frequencies for the magnetically doubly refracted rays. Because the curves for these two reflections are found to maintain a fixed relation, it seems probable that they are due to magnetic double refraction in the $F_{1}$ layer, and that the second component is the extraordinary ray $F_{1}^{\prime}$, having a critical frequency of $f^{\prime}{ }_{F 1}$. The smaller amplitude of the extraordinary ray is probably due to the difference 


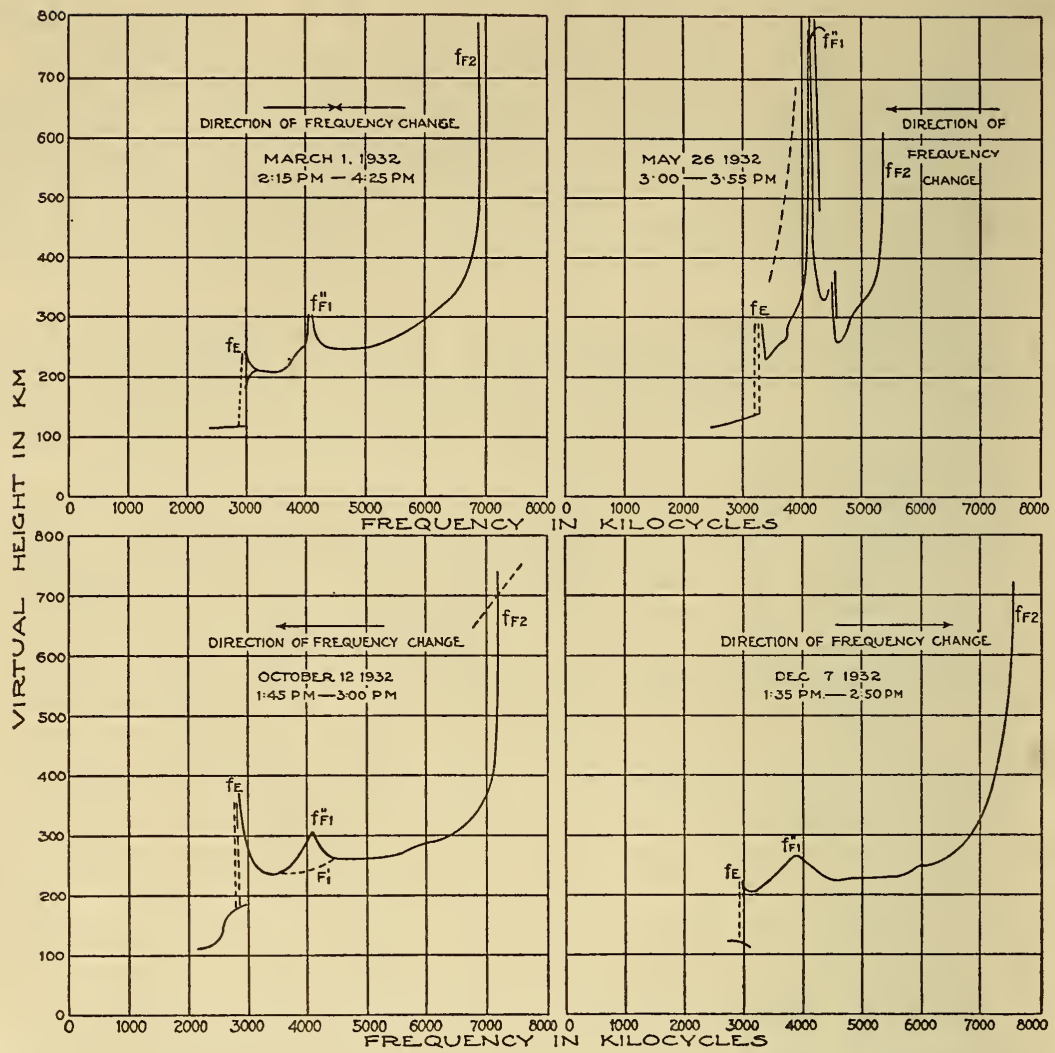

FIGURE 10.-Typical graphs of virtual height vs. frequency showing seasonal changes in retardations at $f^{\prime \prime}{ }_{F 1}$ during the afternoon.

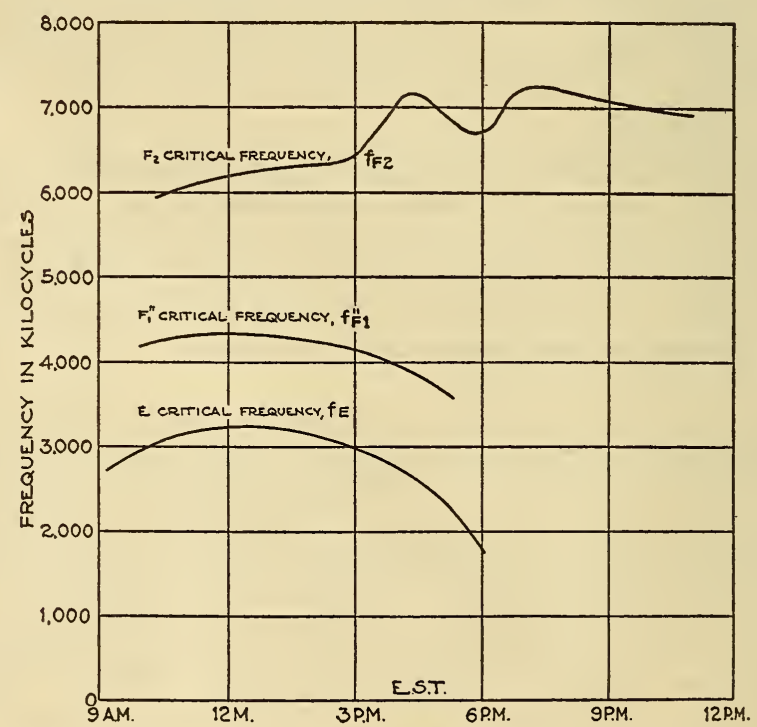

FIGURE 11.-Typical diurnal variations of $f^{\prime \prime}{ }_{F 1}$ showing its relation to other critical frequencies. 

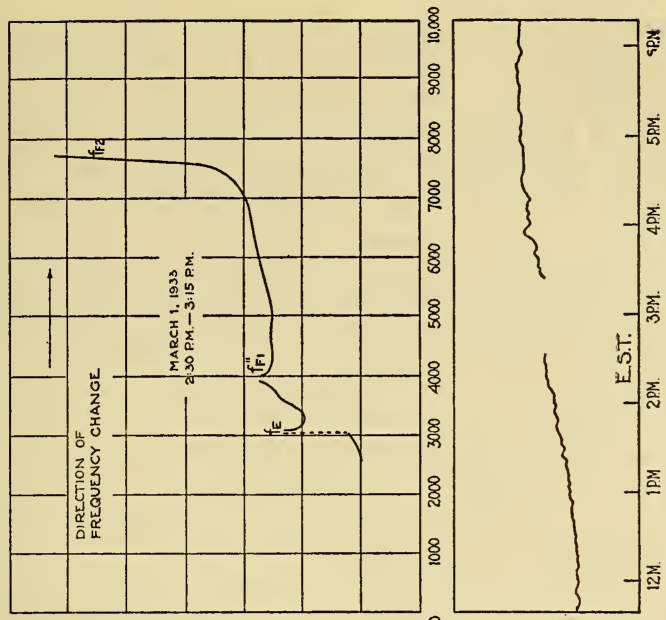

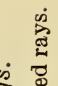

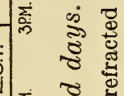

离

I :

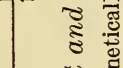

- 芯
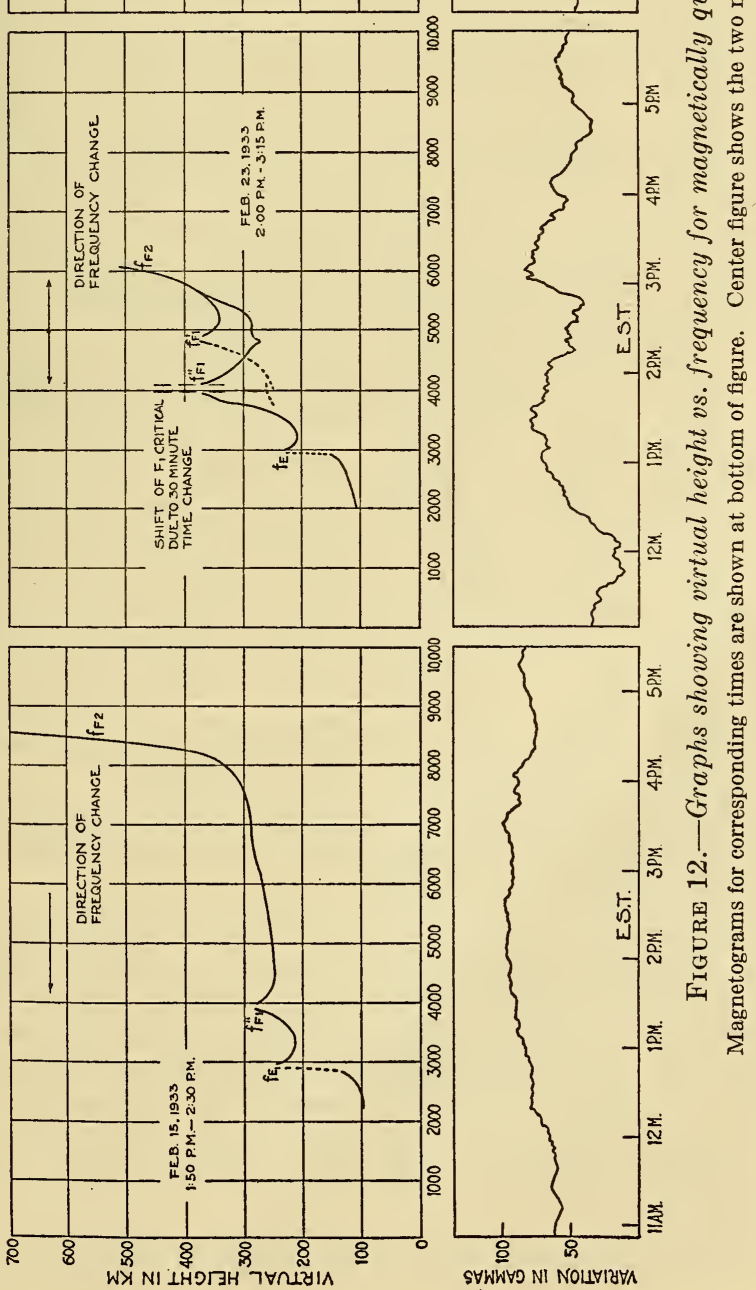
in the absorption of the rays having two different polarizations. This effect has been discussed by Appleton and Ratcliffe. ${ }^{52}$ In addition to these effects, splitting of the main reflection at the critical frequencies through very narrow frequency bands is frequently observed. It appears that all of these effects must be studied ${ }^{53}$ by some means of continuous frequency variation in order to identify their cause more positively.

Few data are available for estimating the variation in the diurnal and seasonal values of the $f^{\prime \prime}{ }_{F 1}$ at vertical incidence. From the available data, however, the variation appears to range from about 3,800

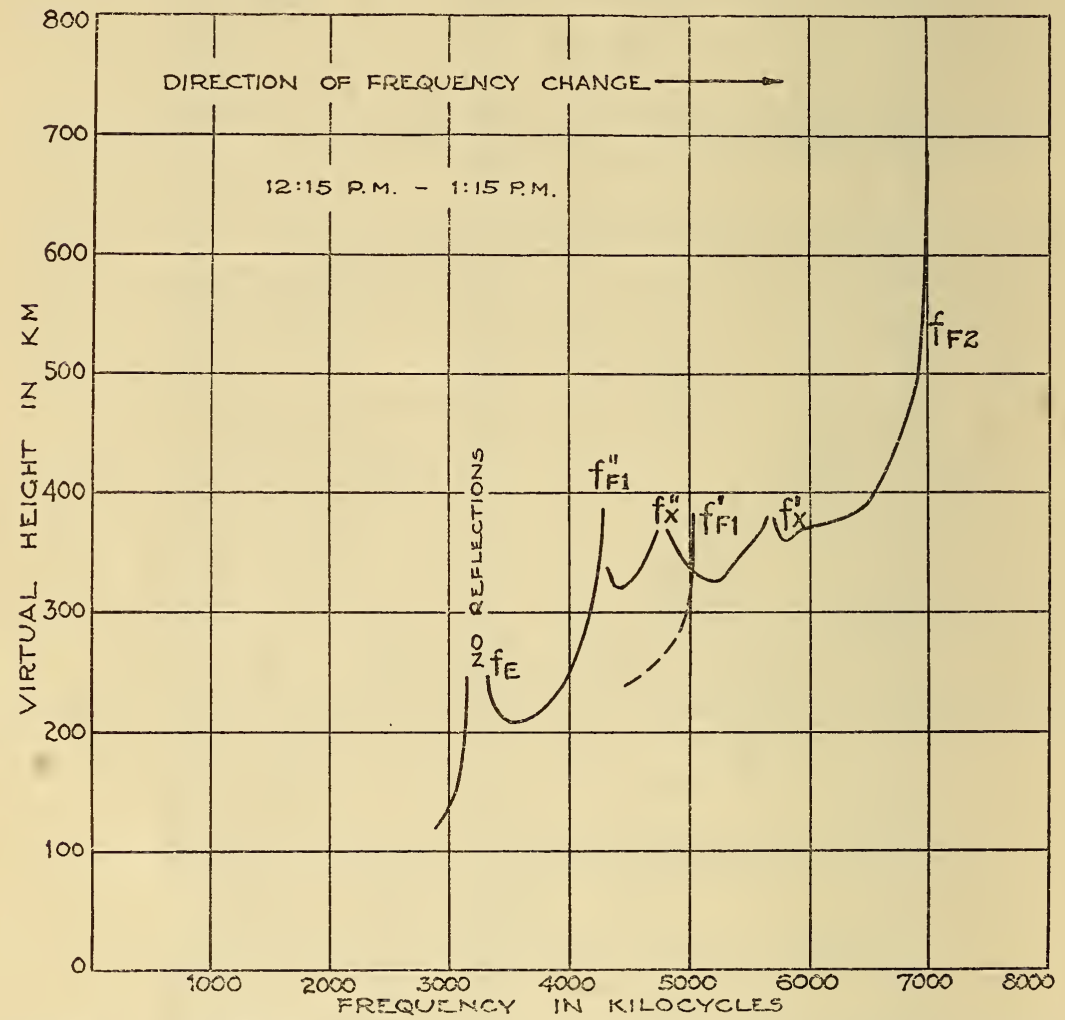

FIGURE 13.-Graph of virtual height vs. frequency showing a number of critical frequencies due to existence of additional irregular layers and their critical frequencies for both magnetically double-refracted rays.

$\mathrm{kc} / \mathrm{s}$ at noon in winter to about $4,500 \mathrm{kc} / \mathrm{s}$ at noon in summer. From equation (4) this would represent a ratio of maximum electron density for the $F_{1}$ layer ranging from 1 to 1.4 from winter to summer. This variation is of the same order as that for the $E$ layer.

Frequently one or more additional critical-frequency phenomena such as shown in figure 13 are found near $f^{\prime \prime}{ }_{F 1}$, indicating the appearance of additional ionized strata in this region. These have not been observed to appear regularly from day to day as is the case with the

\footnotetext{
52 See footnote 28, p. 18.

63 See Note on a Multi-Frequency Automatic Recorder of Ionosphere Heights, T. R. Gilliland, B.S. Jour. Research (RP608), October 1933, describing a practical method of making such observations.
} 
layers just discussed. It is seen that the disappearance of the $F_{1}$ critical frequency in the evening cannot be easily explained on the basis of recombination because of the relatively slow decrease in critical frequency. It seems possible that the $F_{1}$ and $F_{2}$ layers may drift together to form a single layer under these conditions.

Some correspondence appears to exist between phenomena at $f^{\prime \prime}{ }_{F 1}$ and terrestrial magnetic disturbances. Comparisons of the pulse retardation at $f_{F 1}^{\prime \prime}$ with disturbances in the horizontal component of the terrestrial magnetic field indicate that during disturbed periods retardations are often longer and subject to greater absorption than during undisturbed periods. Such phenomena are most easily recognized during the afternoon in summer or at midday in winter when $f^{\prime \prime}{ }_{F 1}$ is not ordinarily sharply defined. Figure 12 shows a typical example of such a case. A study of the long retardations of $f_{F 1}^{\prime \prime}$ shows that the virtual height is usually greatest about noon. If the frequency is held constant at the value of the noon $f^{\prime \prime}{ }_{F 1}$, the virtual height of the ordinary ray just passing through the $F_{1}$ and reflected from the $F_{2}$ layer is found to decrease nearly uniformly throughout the afternoon, with the main reflections joining with the $F^{\prime}{ }_{1}$ reflections late in the afternoon. (See fig. 14.) This decrease in virtual height appears to occur for two reasons: (1) Reduction in $f^{\prime \prime}{ }_{F 1}$ during the afternoon (fig. 10$) ;(2)$ reduction in the retardation of pulses at $f^{\prime \prime}{ }_{F 1}$ (fig. 8). Both causes tend to decrease the effect of the $F_{1}$ layer on the virtual heights of the $F_{2}$ layer as the afternoon progresses. The long retardations accompanying $f_{F 1}^{\prime}$ disappear as the afternoon progresses. This effect appears to be independent of the decrease of critical frequency during the afternoon. Information regarding this point is given in a discussion of results obtained during the solar eclipse of August 31, $1932 .^{54}$

Figure 14 shows the uniform decrease in virtual height which occurred during the afternoons of the magnetically undisturbed periods of September 1, 3, and 4, 1932, together with the magnetograms of the horizontal intensity of the terrestrial magnetic field taken by the United States Coast and Geodetic Survey at Cheltenham, Md. The change of virtual height during the disturbed periods of August 27,29, and 30,1932, is shown in figure 15, together with the corresponding magnetograms. It appears from these curves that there is some relationship between the magnetic changes and the virtual-height phenomena. During the major disturbance on August 27, the reflections were completely absent for long periods, apparently on account of abnormal absorption. During the periods of great retardation on the other disturbed days, reflections were small. Such increases in virtual height at a frequency just above $f^{\prime \prime}{ }^{1}$ might be due to a number of causes: (1) An increase in the virtual height at $f^{\prime \prime}{ }_{F 1}$; (2) an increase in $f_{F 1}^{\prime \prime}$; (3) the existence of one or more higher critical frequencies in the $F_{2}$ region which pass through this frequency as they decrease due to recombination; (4) the appearance of a new critical frequency slightly higher than $f^{\prime \prime}{ }_{F 1}$ due to changing ionic gradient in the $F_{2}$ layer.

An increase in $f_{F 1}^{\prime \prime}$ would represent an increase in ionization of the $F_{1}$ layer under these conditions. (1), (3), and (4) might all occur as the result of a change in the ionic gradient of the $F_{1}$ layer or of unusual ionic strata between the usual $F_{1}$ and $F_{2}$ layers.

\footnotetext{
34 Kirby, Berkner, Gilliland, and Norton. B.S.Jour. Research, December 1933.
} 

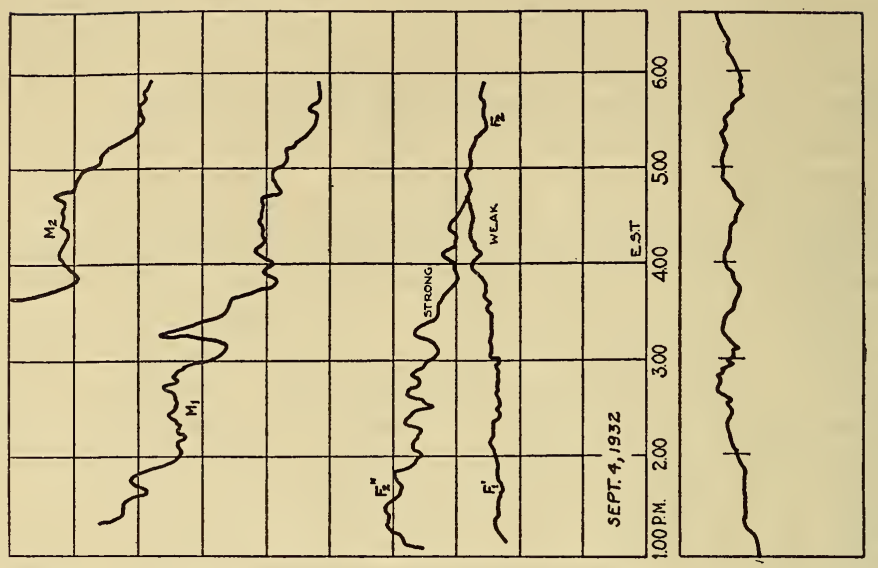

के
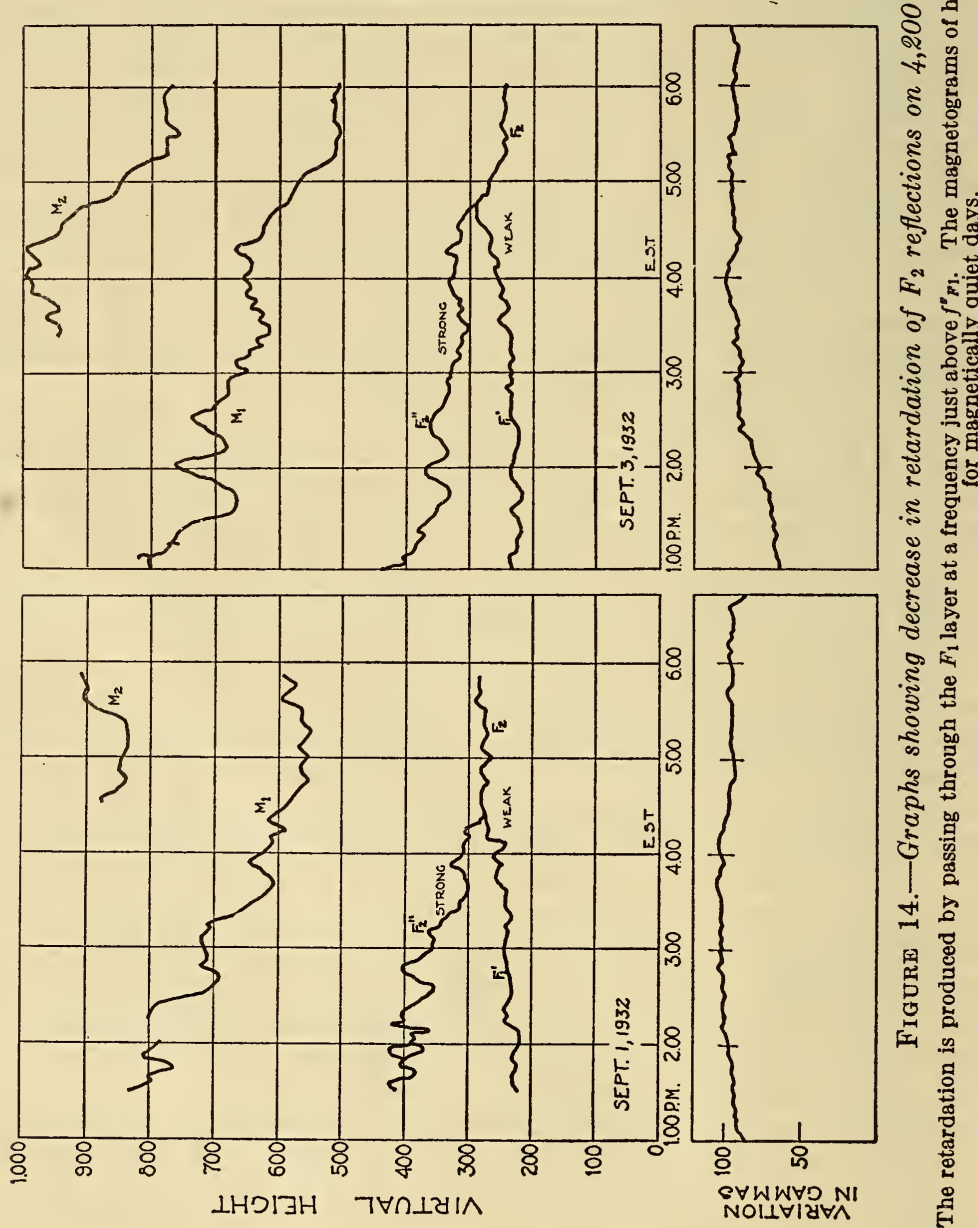

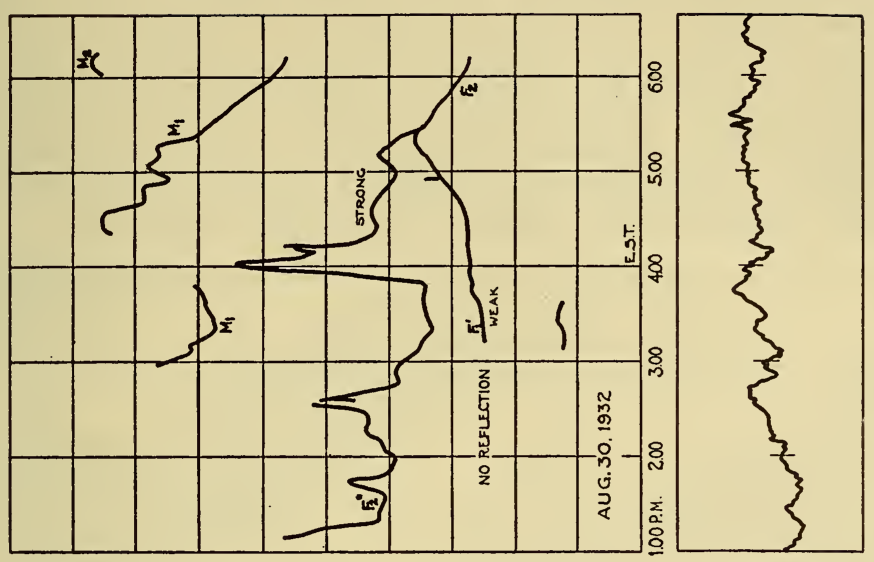

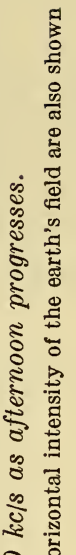
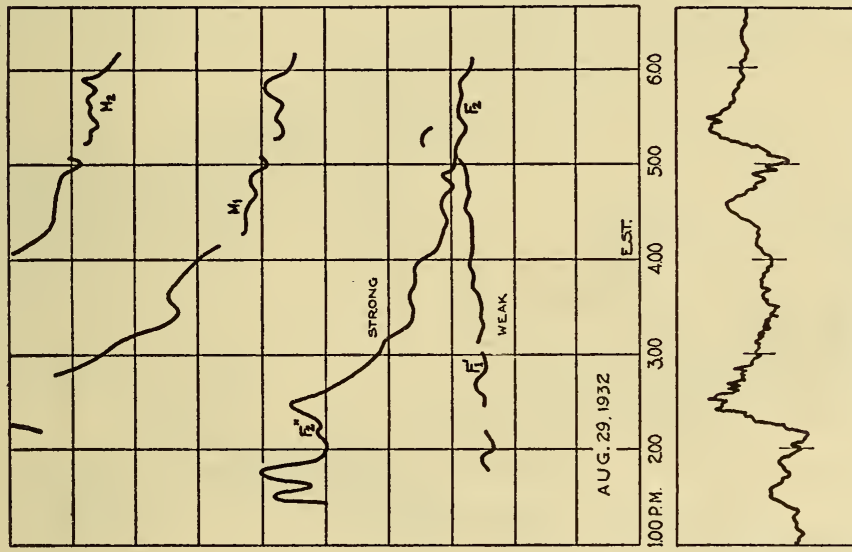

ชิ

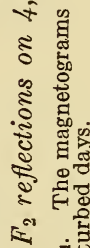

位运苟

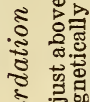

임

.ह :

\&

क

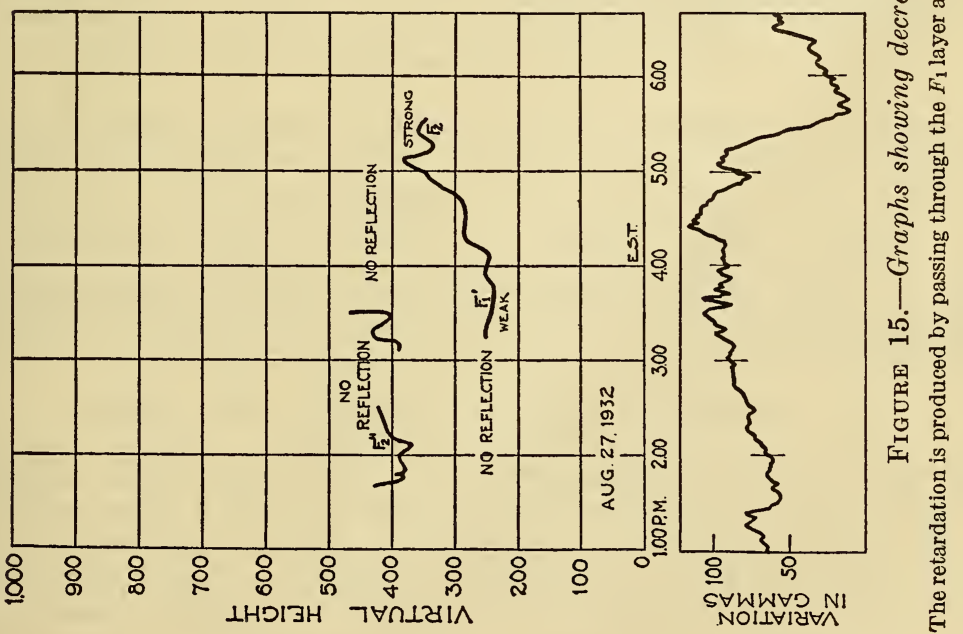


Figure 16 shows the envelopes of the virtual heights for the undisturbed days, with the virtual heights for the disturbed days superimposed, to illustrate the magnitude of the variation shown in figures 14 and 15 . It must be noted that in all cases shown in figures 14 and 15 , the normal virtual heights of the $F_{2}$ layer were observed simultaneously with separate equipment on higher frequencies. This is typically demonstrated in figures 21 and 22 , where the 4,000 to $4,300 \mathrm{kc} / \mathrm{s}$ contours cross those for the higher frequencies.

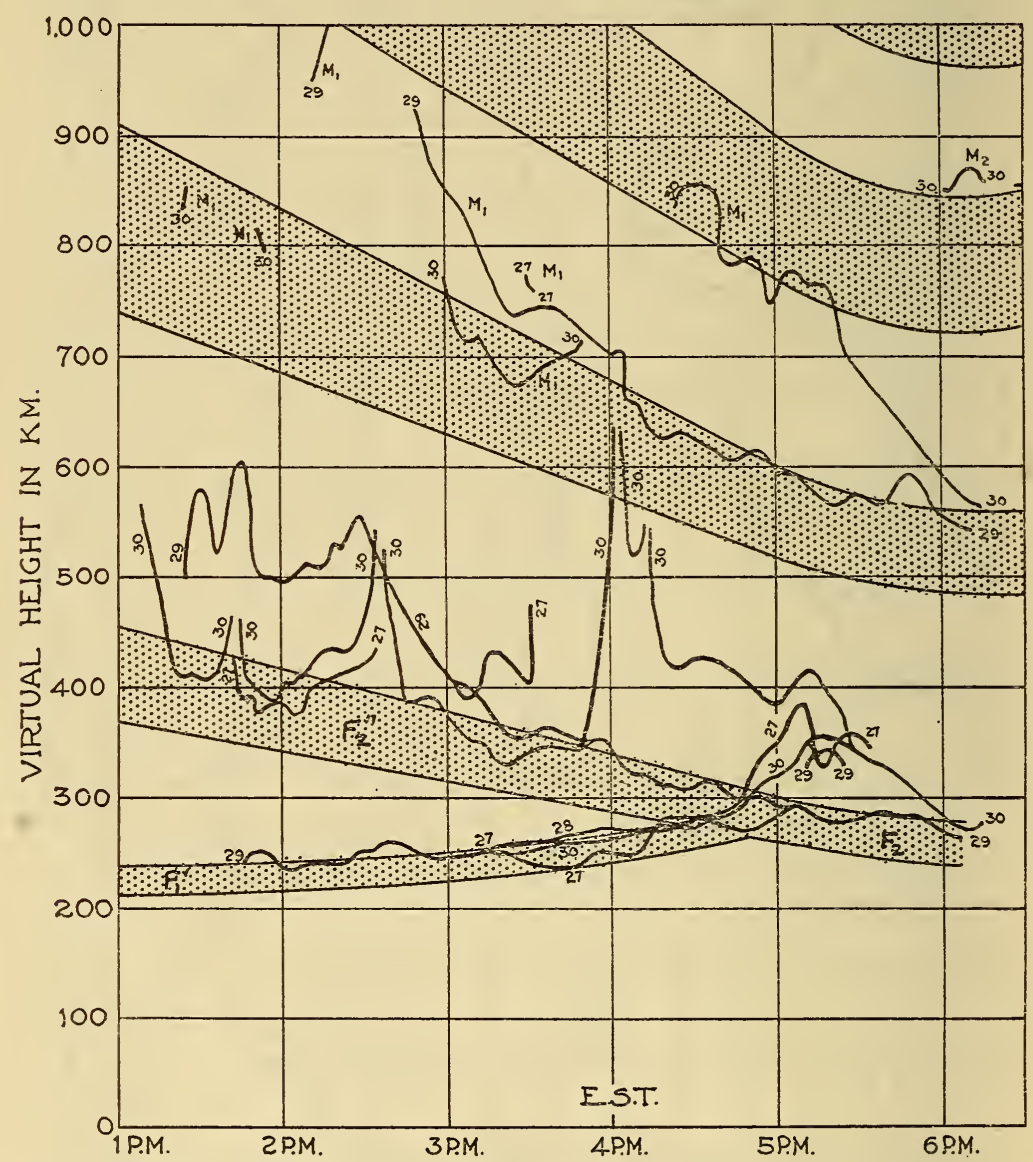

Figure 16.-Envelopes of the virtual heights for 4,200 $\mathrm{kc} / \mathrm{s}$ for undisturbed days, with the virtual heights of the disturbed days superimposed for the days shown in Figures 14 and 15.

\section{INVESTIGATIONS OF THE $F_{2}$ LAYER}

As the frequency is increased above $f^{\prime \prime}{ }_{F 1}$, the virtual height of the ordinary ray falls to values which are usually somewhat higher than those of the $F_{1}$ layer. With further increase in frequency, the virtual height is found to increase rapidly to very great values. This is illustrated in figures 7,8 , and 10 for various diurnal and seasonal variations. We have arbitrarily termed the frequency at 
which the maximum slope of this sudden increase in height takes place as the $F_{2}$ critical frequency, and denoted this frequency as $f_{F 2}$.

As the frequency is increased through $f_{F 2}$, the reflections become rapidly smaller in magnitude as the virtual height increases, finally disappearing entirely. Above this frequency either no reflections at all are returned, or the reflections are greatly retarded and extremely small, and variable in magnitude and virtual height. These "scattered reflections" are discussed in a later section. The $F_{2}$ critical frequency therefore represents, at vertical incidence, the highest frequency which returns reflections of any appreciable magnitude.

The $F_{2}$ critical frequency is subject to certain diurnal and seasonal variations, but these variations do not occur in phase with, or in the

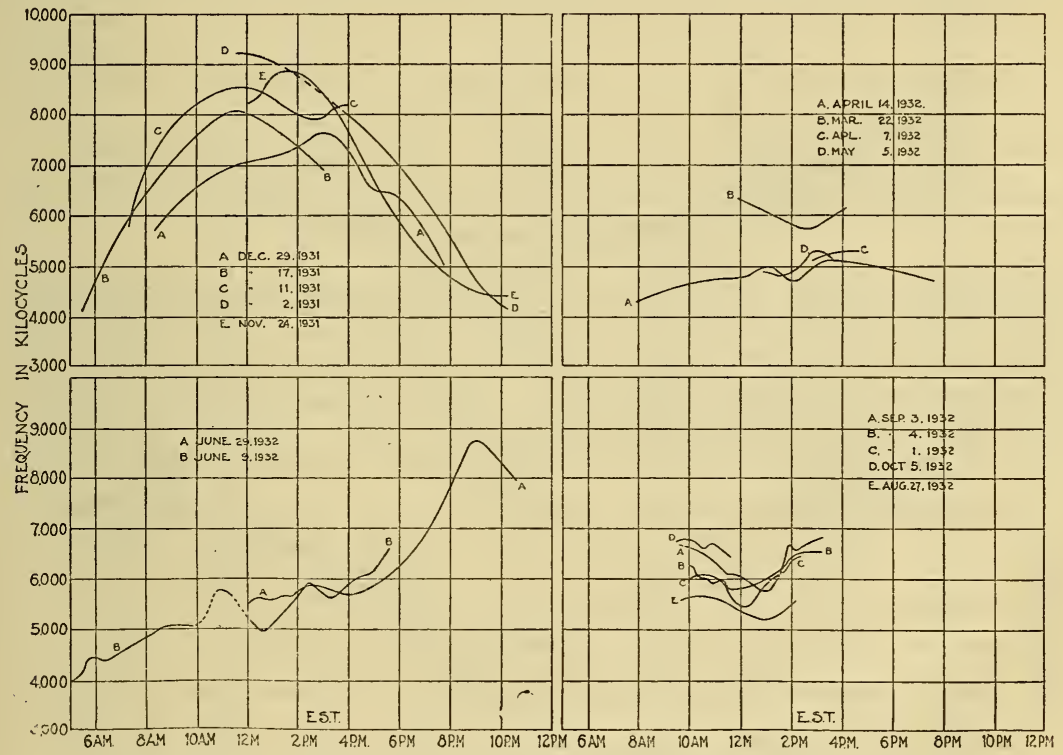

FIGURE 17.-Seasonal variation of diurnal characteristic of $f_{F 2}$.

same manner as $f_{E}$ and $f^{\prime \prime}{ }_{F 1}$. Furthermore, the day-to-day variations are large compared with the small day-to-day variations observed for $f_{E}$ and $f^{\prime \prime}{ }_{F 1}$. "The diurnal characteristic is found to vary quite differently for different seasons. Figure 17 shows this seasonal variation in diurnal characteristic. The winter values of $f_{F 2}$ are seen to have a diurnal characteristic reaching a maximum about noon. This is somewhat similar to variations in $f_{E}$ and $f^{\prime \prime}{ }_{F 1}$, but much more irregular and variable. The springtime values of $f_{F 2}$ show a flatter diurnal characteristic, falling after sunset; while the summer values of $f_{F 2}$ are generally found to rise throughout the day, reaching a maximum after sunset. The retardations at $f_{F 2}$ for all seasons are of the same order of magnitude. (See fig. 10.) Figure 18 shows the seasonal and dayto-day variation in noon and 2 p.m. values of $f_{F 2}$. Figure 19 shows the average variation during the 4 years in which the observations were made. Figure 20 shows the diurnal characteristic for a winter day on which $f_{F 2}$ was high. 

data:

Several important experimental facts are to be obtained from these

(1) The values of $f_{F 2}$ are higher at midday in winter than at midday during the summer by a large factor. This is distinctly the reverse of the trend of $f_{E}$ and $f^{\prime \prime}{ }_{F 1}$.

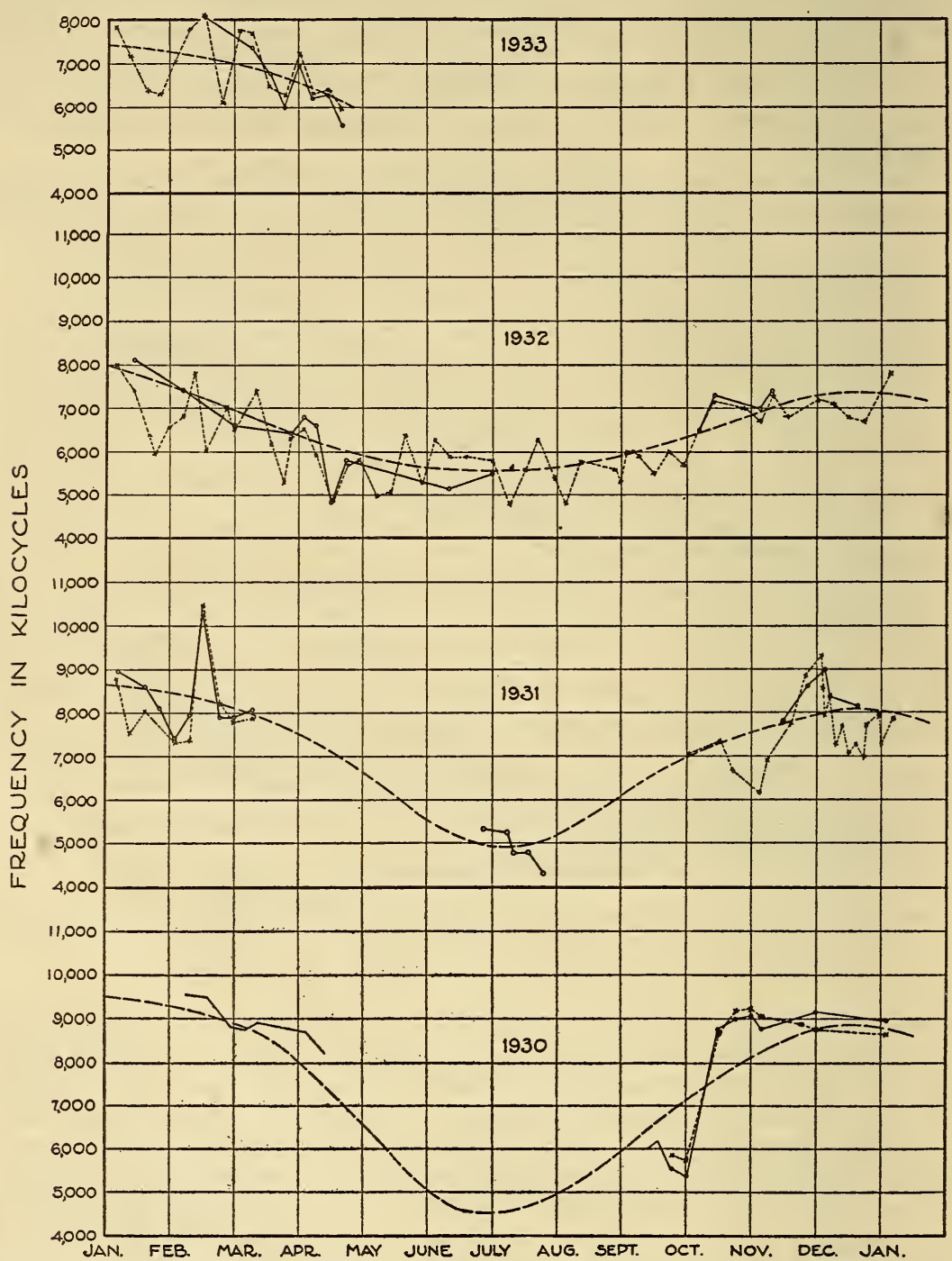

FIGURE 18. - Seasonal and day-to-day variation in noon and 2 p.m. values of $f_{F 2}$. noon - - - -2 p.m.

(2) The values of $f_{F 2}$ reach a maximum some time near noon in the winter, but usually somewhat after sunset in the summer, while the values of $f_{E}$ and ${f^{\prime \prime}}_{F 1}$ regularly reach a peak at noon throughout the year.

(3) The values of $f_{F 2}$ vary widely from hour to hour and from day to day, while values of $f_{E}$ and $f_{F 1}^{\prime \prime}$ for the same time vary only slightly. 
(4) The values of $f_{F 2}$ do not show a symmetry of diurnal characteristic about noon for all seasons as do those of $f_{E}$ and $f^{\prime \prime}{ }_{F 1}$.

The characteristic diurnal changes in virtual heights are shown in figure 21 for December 21, 1932, and in figures 22 and 23 for April 5 and 12, respectively. (See fig. 8 for additional data on fig. 23.)

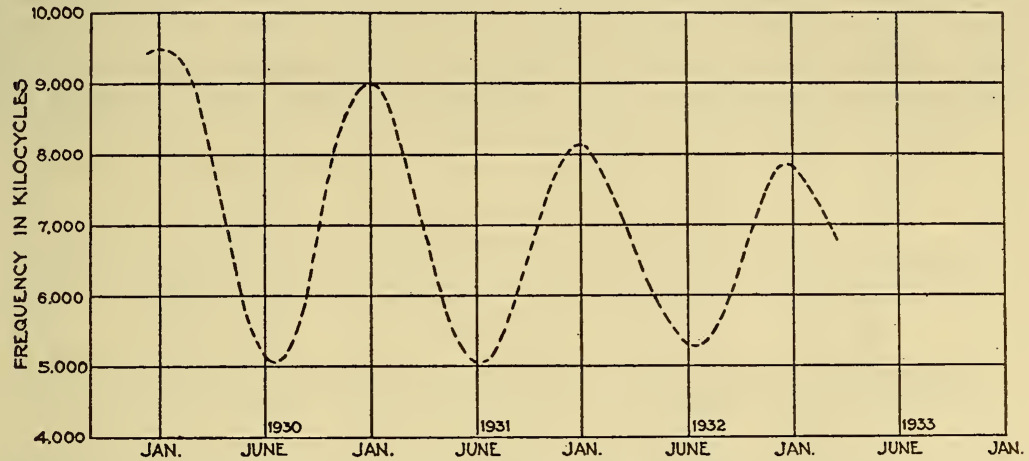

FIgURE 19.-Average variation as shown in figure 18, plotted to indicate change in average values from year to year.

These figures are "virtual height contour maps" plotted against time and frequency. It is seen that the highest critical frequency in December which occurs in the afternoon is accompanied by the lowest virtual heights of the $F_{2}$ layer. A marked dip in this contour occurs at about 1:30 p.m. The diurnal characteristic of $f_{F 2}$ for this period is shown in figure 17. This situation is entirely changed as summer

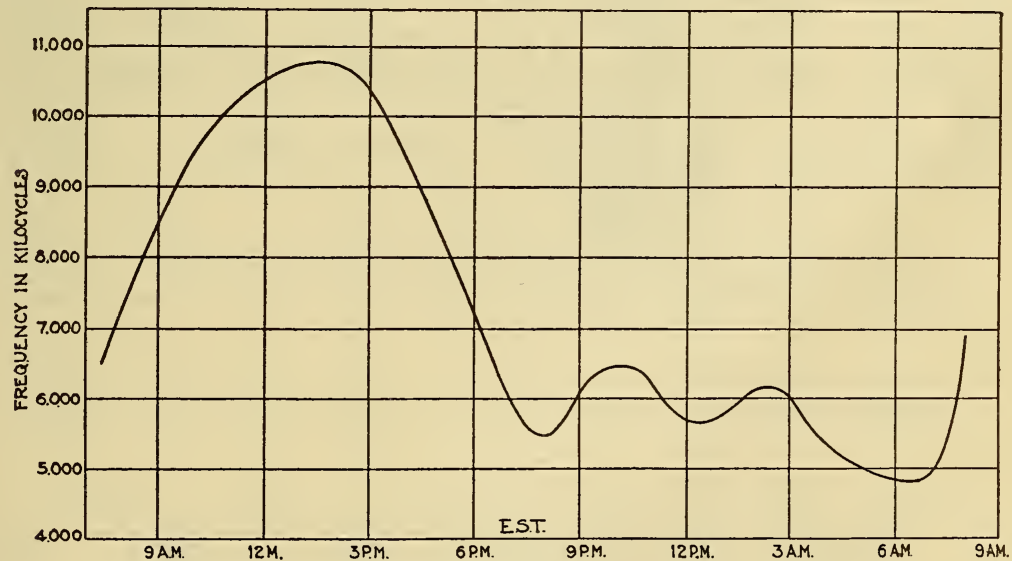

FIgURE 20.-Diurnal characteristic for a winter day of high $f_{F 2}$.

approaches, as is seen from figures 22 and 23 . Here $f_{F 2}$ (shown in fig. 8 for fig. 23) has a peak in the evening at about 7:30 p.m. during April, and the contours show a definite dip in the virtual height at this time. In addition, the irregular hour-to-hour variations of $f_{F 2}$ appear in the contours.

In general, the diurnal characteristic just discussed changes with season, the major dip in the contours, with the accompanying highest 
critical frequency, occurring latest in the evening in midsummer. This brings out another important fact:

(5) The lowest virtual heights of the $F_{2}$ layer for all frequencies at which reflections are returned usually occur at about the same time as does the maximum $f_{F 2}$, irrespective of the time of day at which this occurs. A study of figures 12-21 also serves to illustrate this fact.

It is observed that, during midsummer, reflections from the $F_{2}$ layer often entirely disappear for a period of several hours around noon.

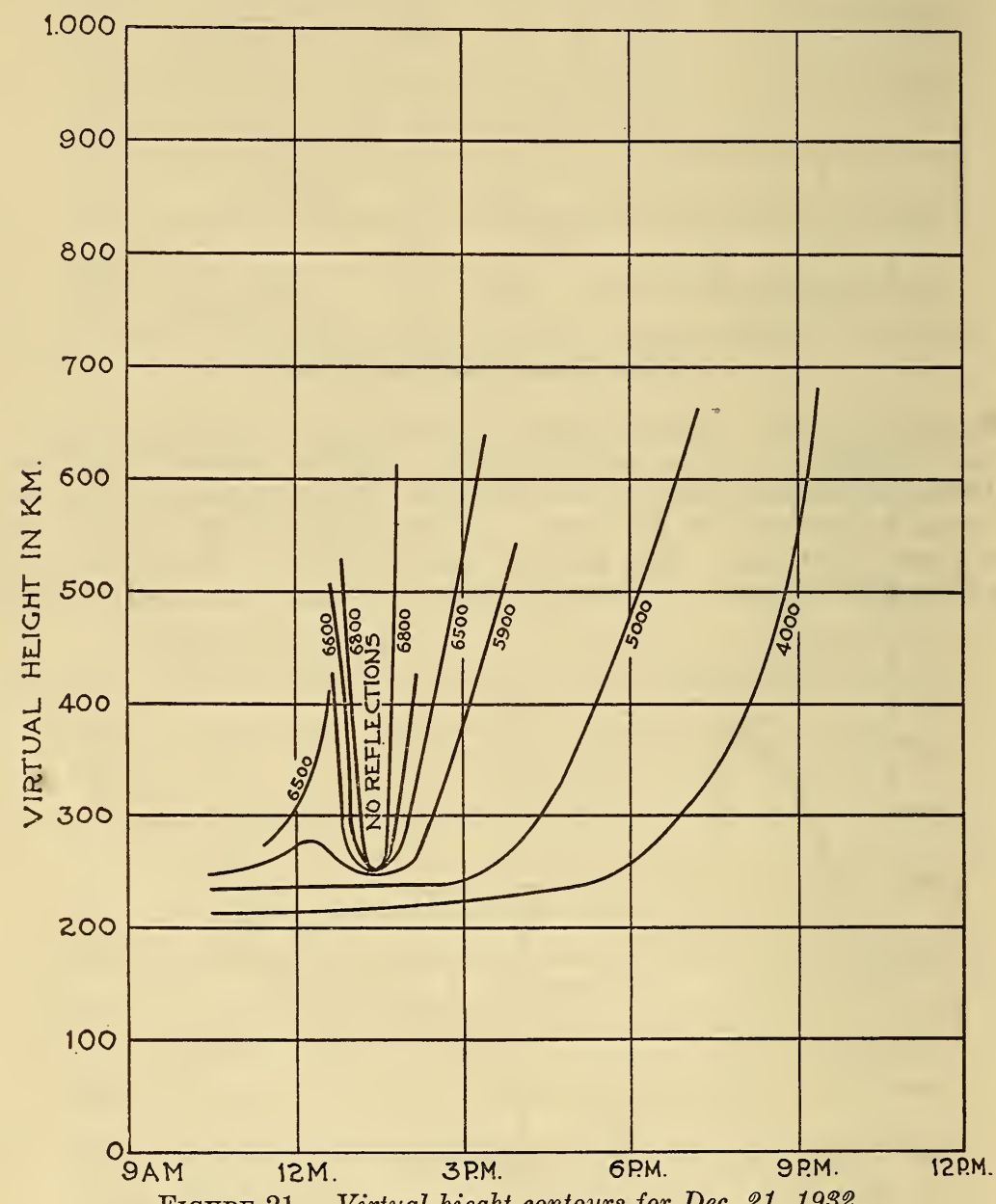

FIGURE 21.-Virtual hieght contours for Dec. 21, 1932.

This disappearance is preceded by a very marked reduction in intensity, and it seems that the reflections finally disappear entirely without a decrease in $f_{F 2}$ through the frequency range in which reflections were previously returned from the $F_{2}$ layer.

It will be seen that while the maximum ionizations for the $E$ and $F_{1}$ layers generally follow the seasonal and diurnal variations of the sun, $f_{F 2}$ shows the following major deviations from this form of variation. From our observations, (1) the maximum value of $f_{F 2}$ bears no fixed 
relation to the altitude of the sun during any season, (2) the maximum noon value of $f_{F 2}$ occurs when the south declination of the sun is the greatest, (3) when the north declination of the sun is the greatest, the maximum $f_{F 2}$ occurs after sunset.

It is apparent that $f_{F 2}$ is subject to effects not evident in the case of the lower layers. Several possible causes of such effects will be considered and discussed. (1) that the ionization of the $F_{2}$ layer is due, in part at least, to external ionizing forces not directly associated with

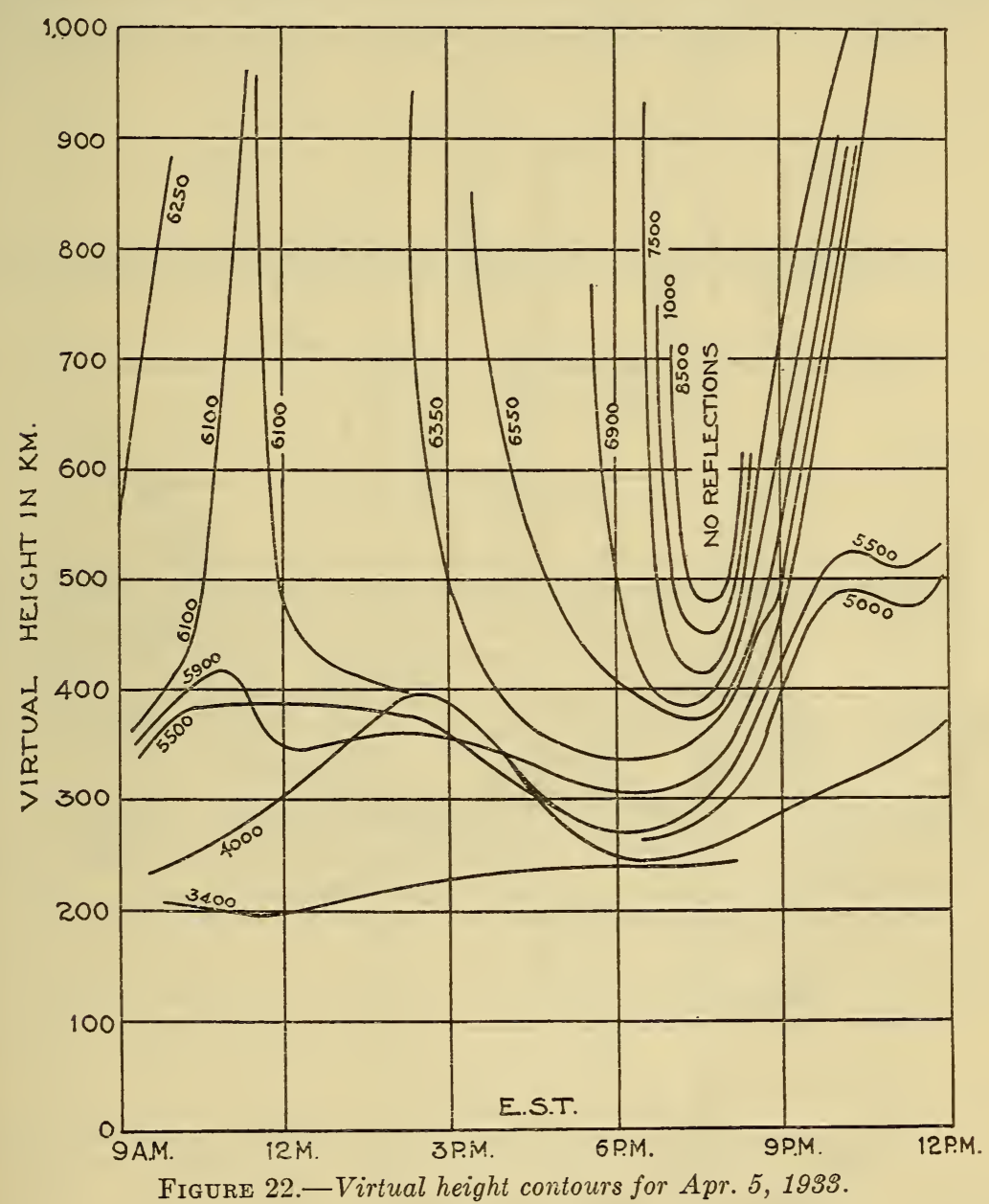

the sun, (2) that ionization of the $F_{2}$ layer is due, in part, to drift of electrons from other ionized regions, and (3) that the variations of $f_{F 2}$ depend upon absorption and not upon ionization, at least during those parts of the day in which the deviations occur, when the ionization is associated with the sun in the same manner as that of the lower layers.

We will discuss the reasonableness of these possible causes in the light of the data at hand. 
The fact that the ionization of the $F_{2}$ layer has a diurnal variation which is associated with the solar day would seem to indicate that the origin of the ionization is solar rather than cosmic.

A possible drifting together of the $F_{1}$ and $F_{2}$ layers so as to form a single layer has been mentioned. Such a drift would appear to be a comparatively slow process, but it might be possible to obtain a concentration of ions in this manner. Rapid changes in $f_{F 2}$ might be explained on the basis of a nonuniform and changing horizontal dis-

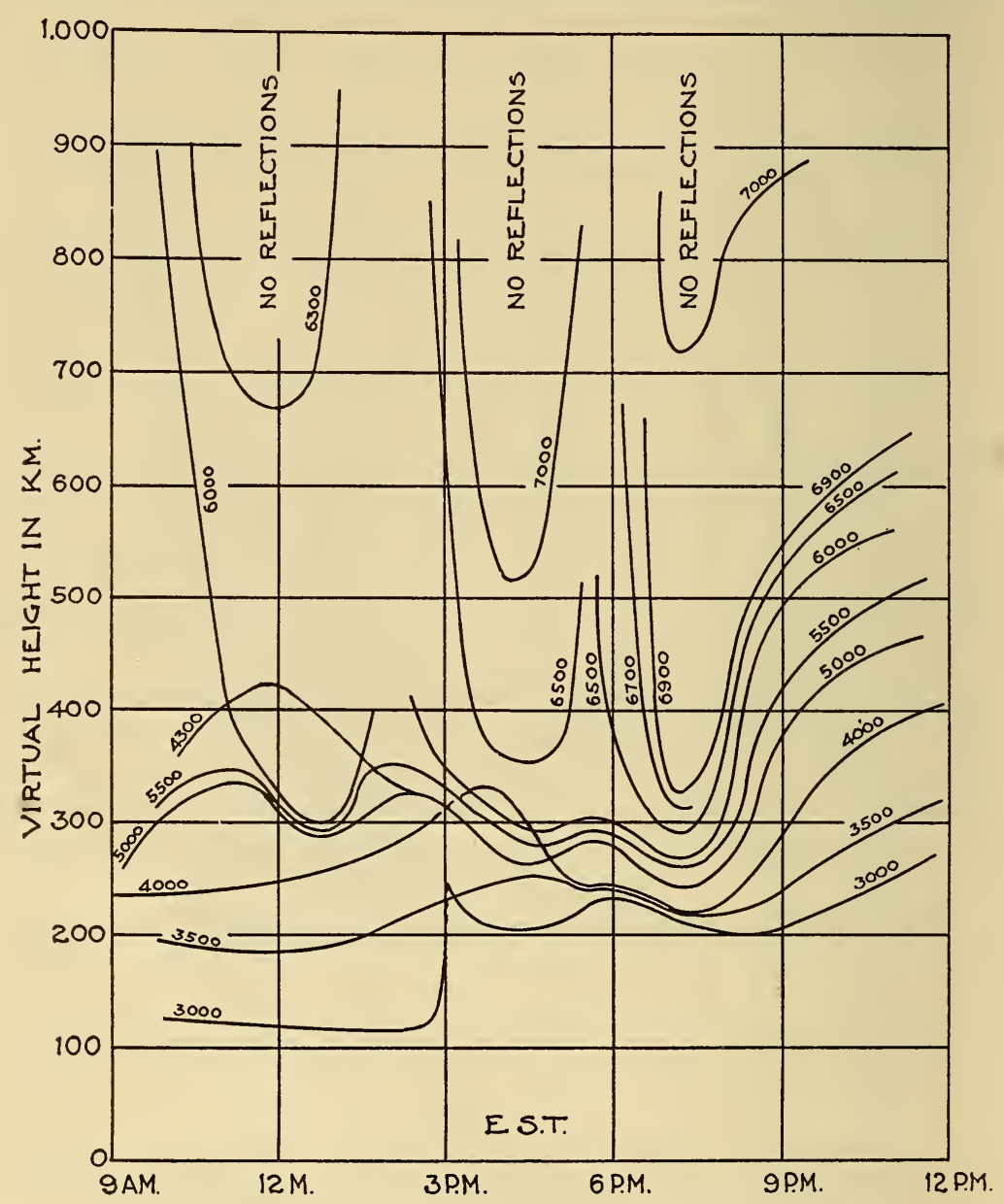

FigURe 23.-Virtual height contours for Apr. 12, 1933.

tribution of ions in the $F_{2}$ layer. It is difficult, however, to account for the lower ionization in the summer day than in the winter day on such a basis unless there are rather large and complex changes in atmospheric distribution with season.

If we assume that the chief source of ion concentration in the $F_{2}$ layer is direct radiation from the sun, as seems to be the case with the lower layers, our conception and definition of $f_{F 2}$ cannot be the same as that given for the critical frequencies of the lower layers. 
Critical frequency has been defined for the $E$ and $F_{1}$ layers as the lowest frequency at which waves penetrate these layers, and it therefore serves as a measure of the maximum ionization of these layers. If, as might be expected, the maximum ionization for the $F_{2}$ layer takes place about midday throughout the year, we must consider, during the summer daytime at least, that $f_{F 2}$ depends upon absorption rather than upon penetration. We will therefore discuss this possibility.

As has been previously mentioned, a number of authors have shown that the group, or signal, velocity in an ionized medium may be subject to great retardation. It has been shown that

$$
u=\frac{c}{n+\omega \frac{d n}{d \omega}}
$$

where $u$ is the group or signal velocity.

For a dispersive medium containing free electrons, this becomes:

$$
\begin{gathered}
u=\frac{c}{n+\omega \frac{d}{d \omega}\left(1-\frac{4 \pi N e^{2}}{m \omega^{2}+a\left(4 \pi N e^{2}\right)}\right)^{1 / 2}} \\
=\frac{c n}{1-a\left(1-n^{2}\right)^{2}}
\end{gathered}
$$

According to this relation, large reductions in group velocity occur only when $n$ approaches zero. The actual retardation experienced in the layer is seen to depend upon the ionic gradient for the medium just described near the density at which $n$ becomes zero.

Breit ${ }^{55}$ has shown that for decreasing ionic gradients, very great retardations may be expected, and has computed possible retardations for a number of postulated distributions. For very high ionic gradients the wave travels only a short distance in a region of low group velocity before being returned, while for decreasing gradients the wave must travel for some distance in a region of reduced group velocity, where $n$ is very nearly but not quite zero, and is therefore subject to great retardation. This might be true over a wide frequency range for a thick, highly-ionized layer of decreasing gradient. It appears, therefore, that the retardation found at $f_{F 2}$ might be explained on the basis of increasing ionization of decreasing gradient as well as of penetration due to low ionization.

It has been shown by Pedersen ${ }^{56}$ that when such conditions cause long retardation, complete absorption should occur.

Because of difficulty in making valid assumptions regarding conductivity and resulting absorption under these conditions, we will refer to experimental data to determine the possibility of complete absorption due to such electron distribution. A case of this sort of complete absorption which can be positively identified in the presence of a higher reflecting stratum is shown in figure 15 for August 27, 1932. Here the reflections at $4,200 \mathrm{kc} / \mathrm{s}$ were completely absent for an extended period due to conditions in the $F_{1}$ layer while at frequencies as much as $1,500 \mathrm{kc} / \mathrm{s}$ higher good reflections were returned. The 
value of $f_{F 2}$ for this period is shown in figure 17 . Such cases are frequently observed at critical frequencies and occasionally throughout bands of several hundred kilocycles no reflections are returned. A study of the data shows that when the virtual height of a layer changes only slowly with frequency, the reflection strength and the number of multiples is the greatest. The reflections become small and the multiples disappear when the virtual height changes rapidly with frequency. Great virtual heights occurring at critical frequencies are usually associated with high absorption.

From this it seems possible that above $f_{F 2}$ there may be complete absorption as well as long retardation, the ionization increasing continuously but with a decreasing gradient. If some mechanism of this sort is assumed to limit the maximum frequency at which reflections are returned, $f_{F 2}$ then indicates a boundary above which the ionization gradient decreases sufficiently rapidly to cause long retardation and large absorption, rather than the maximum ionization in the $F_{2}$ layer.

It is believed that the observed data can be qualitatively explained in a satisfactory manner on this basis. During the winter day there may be comparatively high ionic gradients due to the low incidence of the ionizing radiation on this layer. During the summer, this radiation at a more nearly normal incidence may create a more diffuse layer due to its greater penetration, thus causing long retardation and high absorption over a wider band of frequencies until such time as recombination or ion drift at the bottom of the layer cause higher gradients to appear. At such a time the critical frequency may be expected to rise and the virtual heights decrease as shown in figures 20 and 21.

Observations at night frequently show one or more secondary increases in $f_{F 2}$ after the main increase, with corresponding decreases in virtual height. These secondary increases might be due either to small increases in ionization or to increased ionic gradients caused by recombination or changes of distribution of the ions in the layer. So far, it has not been possible to determine with certainty whether the phenomena associated with $f_{F 2}$ are due to penetration or absorption but the evidence leads to the belief that both factors may be involved. If this is true, $f_{F 2}$ frequently is not a measure of the maximum ionization of the $F_{2}$ layer.

From the foregoing discussion, it appears that the midday values of the $F_{2}$ ionization might exceed the values corresponding to the maximum value of $f_{F^{2}}$ by a considerable amount. On this basis it can be estimated from equation (4) with $a=0$ that this maximum ionization reaches $1.5 \times 10^{6}$ electrons per $\mathrm{cm}^{3}$ frequently, and is known to be at least $2.5 \times 10^{6}$ electrons per $\mathrm{cm}^{3}$ in the evening on certain occasions. With $a=1 / 3$ the corresponding electron densities are $2.25 \times 10^{6}$ and $3.75 \times 10^{6}$.

A study of the figures indicates that the heights of the $F_{2}$ layer may be estimated to be below $250 \mathrm{~km}$. This estimate is based upon the same approximations as were mentioned in connection with the $F_{1}$ layer.

Compared with the fairly stable values of $f_{E}$ and $f_{F 1}$ during the day, $f_{F 2}$ is subject to small rapid fluctuations superimposed upon its general diurnal characteristic. This results in rapid changes in virtual height such as shown in figure 24 . 
Because of the rapidity of these fluctuations, it is not valid to assume that time changes are negligible while working near $f_{F 2}$ with a single equipment. For this reason we hesitate to comment on such criticalfrequency phenomena as are shown in figure 25 . It is possible that such irregular changes occur with time more rapidly than the frequency can be changed. It is possible at least in the case of figure $25(d)$, however, that the two critical frequencies shown were both real, and that a temporary double stratification appeared in the $F_{2}$ layer during the first run, the higher stratum disappearing by the time of the second run thus leaving only the first critical frequency. Such phenomena have thus far been observed only during the summertime. Further evidence as to the possible variable stratification of the $F_{2}$ layer could be obtained by making simultaneous experiments with several equipments operating at different frequencies.

No obvious relation between magnetic disturbances and values of $f_{F 2}$ is apparent. Very high and very low values of $f_{F 2}$ are often observed during magnetic disturbances and seem to occur less frequently during undisturbed periods. Normal values of $f_{F 2}$ have also been observed during disturbed periods. If the
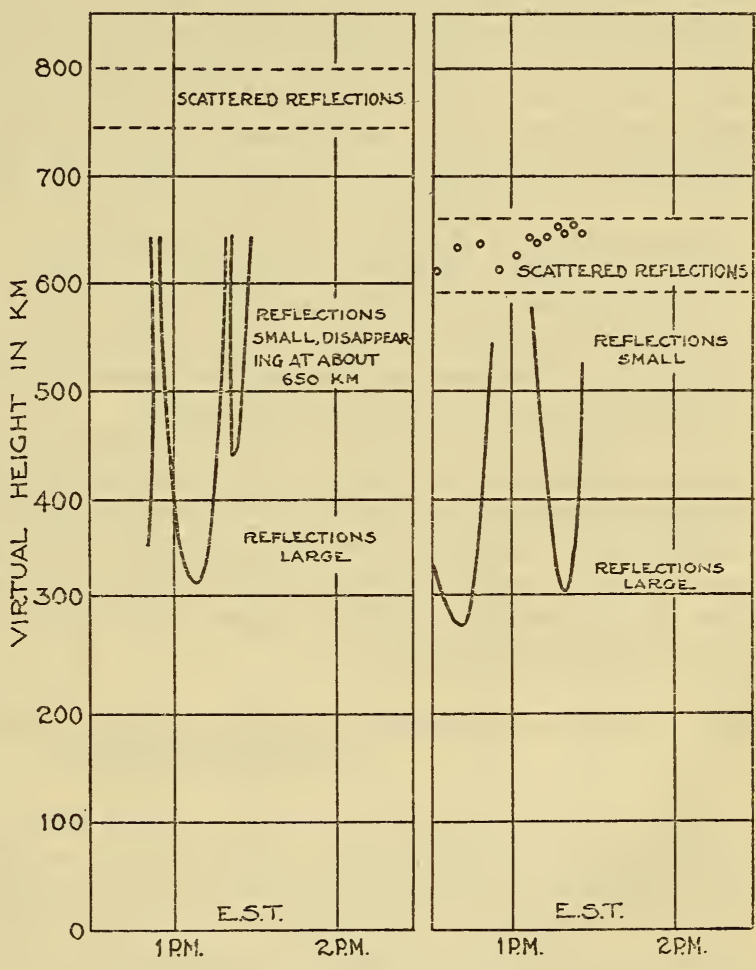

FIgURe 24.-Characteristic variations in virtuai height near $f_{F 2}$. This shows rapid variation of $f_{F 2}$. values of $f_{F 2}$ are largely determined by ionic gradient and absorption, it is reasonable to expect that magnetic disturbances might produce effects not easy to interpret.

\section{SCATTERED REFLECTIONS}

The "scattered reflections" mentioned as occurring above $f_{F 2}$, appear to be of a nature quite distinct from the reflections previously discussed. These reflections are found to appear first at a frequency somewhat below $f_{F 2}$ and at a virtual height generally above $600 \mathrm{~km}$. Their virtual height appears to be independent of changes in the 
virtual height of the $F_{2}$ layer as shown in figure 22. The average virtual height increases slowly with frequency, often extending to above 1,000 to $1,500 \mathrm{~km}$ at frequencies well above $f_{F 2}$. These are characterized by a small and variable amplitude, and a rapid variation, through a small range, of virtual height, best described as "rapidly popping in and out at various heights."

During $F_{2}$ critical frequency runs, as the virtual height of the $F_{2}$ layer was observed to increase rapidly, the $F_{2}$ reflection was usually completely absorbed before reaching the virtual heights of these scattered reflections, which were practically unchanged by small frequency variations in the winter. Scattered reflections have been observed on the highest frequencies so far used in these measurements (that is, about $12,000 \mathrm{kc} / \mathrm{s}$ ). It is possible that this is the same phenomenon as that described by Taylor and Young ${ }^{57}$ and others in connection with experiments at very high frequencies. No directional measurements have so far been made of their source. During the observations made on March 22, 1933, shown in figure 6, reflections from the higher layers appeared to be completely blanketed out by a heavy E-layer ionization. During this time, reflections which appeared to be identical with the usual "scattered reflections" continued to appear at virtual heights well above that of the last $E$ multiple, and at frequencies near the previous value of $f_{F 2}$, even though the reflections from $F_{2}$ had disappeared.

It is possible that these scattered reflections may be returned at frequencies considerably below $f_{F 2}$, but the relatively great magnitude of the multiple reflections from the lower layers is likely to mask them completely. During the night, when $f_{F 2}$ is not well defined (see fig. 9) and complex reflections of large magnitudes occur above relatively low virtual heights, it is frequently difficult to determine when this effect begins to appear.

\section{SOME CORRELATIONS WITH RESULTS OF RADIO TRANSMISSION}

It is of interest to observe that, using horizontal dipoles as transmitting and receiving aerials, directional toward each other, and over the $25-\mathrm{km}$ land path between stations, the magnitude of the daytime reflections between a frequency somewhat below the $E$ critical frequency and the $F_{2}$ critical frequency, ordinarily greatly exceeds the magnitude of the ground wave. The ratio of field intensities of the sky wave to those of the ground wave often exceeds 100:1. At night, the magnitude of the reflections becomes very much greater, particularly at the lower frequencies. The use of lower angle radiators, such as vertical antennas, of course, greatly reduces this ratio. Because of the effectiveness of the ionosphere as a reflector of waves of low frequency at night, the sky wave and ground wave may be of equal magnitude in an antenna only a very short distance from the transmitting station, even though only a very small amount of energy is radiated upward. This is particularly noticeable if the receiving antenna has a somewhat high-angle characteristic. The introduction of vertical antennas at the receiver serves to discriminate greatly against the high-angle sky-wave energy.

\footnotetext{
57 Taylor and Young, Proc.I.R.E., vol. 16, p. 561, 1928; and vol. 17, p. 1491, 1929.
} 
It is of interest to investigate the relation of the highest critical frequency of the $F_{2}$ layer at vertical incidence to the frequencies of waves received at great distances. The maximum frequency at which waves are reflected from the $F_{2}$ layer is very much less in summer than in winter. The values obtained are believed to be in fair agreement with the results obtained by a number of observers. Burrows ${ }^{58}$ has pointed out that during 1928-1929 for trans-Atlantic transmissions, the highest summertime frequency at which waves could be transmitted across the Atlantic was $22,000 \mathrm{kc} / \mathrm{s}$, while the highest wintertime frequency was $28,000 \mathrm{kc} / \mathrm{s}$. The times of best trans-Atlantic high-frequency transmission shown in Burrows' figures for the various seasons correspond closely with the times of dip in the "virtual height contour maps" for the $F_{2}$ layer when consideration is given to the differences in time existing between the ends of the path.

This agreement might be expected in view of the $F_{2}$ layer results by which it was shown that the absorption was the lowest when the
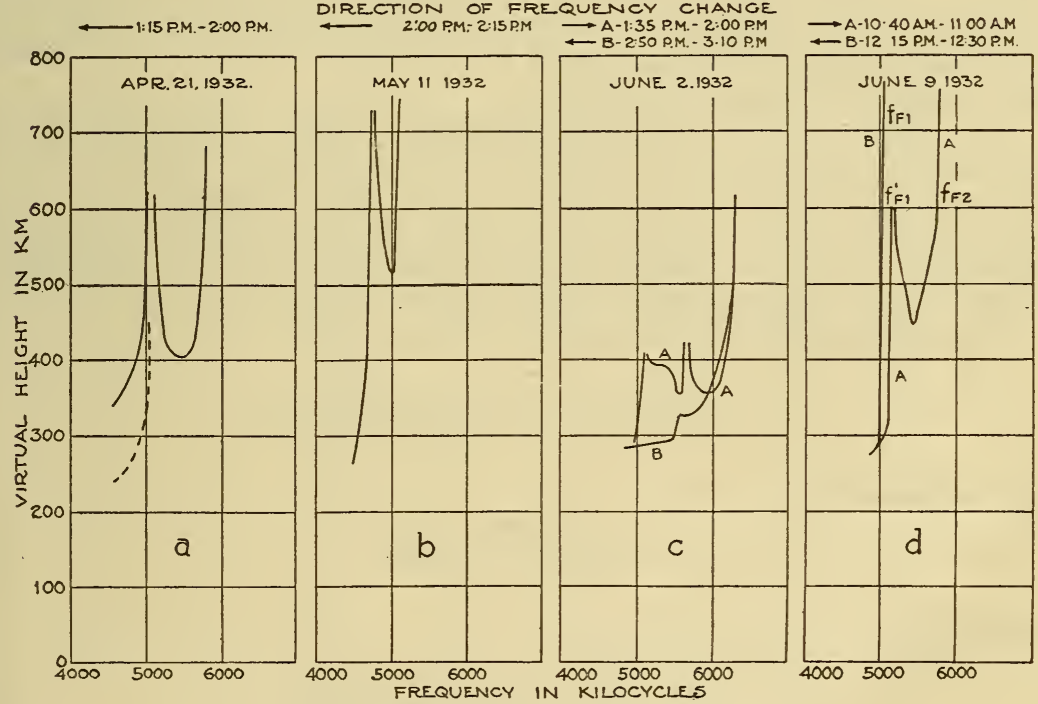

FIGURE 25.-Examples of rapid changes in $f_{F 2}$.

frequency-height curves had the least slope, a condition occurring at the time of highest critical frequency. It can be seen that waves of the highest frequencies are returned over long paths when the highest $\left(F_{2}\right)$ layer appears to be in the most favorable condition for reflection, and in general the diurnal and seasonal variations of such frequencies seem to follow changes in the condition of this layer. At the same time lower frequencies follow the somewhat different diurnal and seasonal variations of the lower layers.

In a previous section, the possibility that the disappearance of reflections might be due to absorption rather than to low ionization was discussed. Burrows suggests that the return of reflections at lower maximum frequencies during the summer than during the winter may be due to absorption. On the basis of this hypothesis, an ion density considerably in excess of that indicated by the maximum criti-

68 Burrows, Proc.I.R.E., vol. 19, p. 1634. 
cal frequency should be expected. It would be difficult to make even approximate estimates, however, because of the lack of data on the physical structure of the atmosphere in this layer. A suitable distribution of such high densities might account for the apparent occasional reflection from the ionosphere of waves at very high frequencies, such as have been frequently observed. It might be presumed that approximately north-south paths would be most uniform for such maximum-frequency transmissions. Such paths in the northern hemisphere would vary from a path running about north-northwestsouth-southwest during winter noon to about north-northeastsouth-southwest during summer evenings. Such paths extending between northern and southern hemispheres, however, would be subject to different seasonal effects as shown. More uniform conditions would probably exist during the afternoon. A detailed knowledge of these effects at different latitudes would make it possible to work out more definitely the conditions to be expected for various paths. It may also be possible that higher layers exist which on account of absorption are not evident at the frequencies so far employed, but which might reflect waves of much higher frequencies at smaller angles under favorable conditions.

It is believed that the disappearance of large reflections for frequencies greater than $f_{F 2}$ represents the skip distance effect. It is of interest to examine the development of a "skip distance" if the limitation of $f_{F_{2}}$ is due to absorption rather than penetration due to low ionization. This possibility has been suggested by T. L. Eckersley ${ }^{59}$ on the basis of experiments carried out over a more extended base line.

From equation (4) at the apex of the ray path

$$
n^{2}=\sin ^{2} \phi=1-\frac{4 \pi N e^{2}}{4 \pi^{2} m f^{2}+a 4 \pi N e^{2}}
$$

Then with $a=0$

$$
N=\frac{\pi m f^{2}}{e^{2}}\left(\cos ^{2} \phi\right)
$$

with $a=1 / 3$

$$
N=\frac{\pi m f^{2}}{e^{2}}\left(\cos ^{2} \phi\right)\left(\frac{3}{2+\sin ^{2} \phi}\right)
$$

This shows that for small angles of incidence (nearly vertical incidence) where $\left(\cos ^{2} \phi\right)$ is nearly unity, the number of ions per $\mathrm{cm}^{3}$ required to return reflections is not much reduced below that required at vertical incidence, and for boundaries of decreasing ionic gradient, the wave will be subject to the same high retardation and absorption observed at vertical incidence under these conditions. At the same time, the length of path subject to this increased absorption is extended horizontally as the angle of incidence, $\phi$, is increased. When the value of $\phi$ becomes large enough to cause the factor $\left(\cos ^{2} \phi\right)$ to depart appreciably from unity, the number of electrons per $\mathrm{cm}^{3}$ required for refraction, and therefore the depth of penetration into the region of decreasing ionic gradient, decreases rapidly, and the length of path in which there is large absorption decreases. From this it might be expected that reflections at frequencies somewhat below $f_{F 2}$, but pene-

${ }^{59}$ See footnote 51, p. 30. 
trating deeply into the $F_{2}$ layer as determined by the curvature of the frequency-virtual height curves, may be subject to a considerable dip in intensity as the distance from the transmitter is increased, followed by an increase as the reflections are returned from a region of higher ionic gradient. It would also seem that absorption would prevent that portion of the layer represented by the steep slope of the frequency-height curves from returning reflections over any considerable distance. On this basis, it can be seen from the figures that a considerable variation in skip distance might be expected from day to day and from year to year. If this picture of the skip-distance phenomenon is correct, it may be expected that the portion of the $F_{2}$ layer represented by the steep slope of the frequency-virtual height curves will cause absorption of waves reaching this region.

Washington, August 23, 1933. 